\title{
Recommendations of the
}

\section{Neuroendocrinology Department of the Brazilian Society of Endocrinology and Metabolism for the diagnosis of Cushing's disease in Brazil}

Márcio Carlos Machado', Maria Candida Barisson Vilares Fragoso', Ayrton Custódio Moreira ${ }^{2}$, César Luiz Boguszewski ${ }^{3}$, Leonardo Vieira Neto 4 , Luciana A. Naves ${ }^{5}$, Lucio Vilar ${ }^{6}$, Luiz Antônio de Araújo ${ }^{7}$, Mauro A. Czepielewski ${ }^{8}$, Monica R. Gadelha ${ }^{4}$, Nina Rosa Castro Musolino", Paulo Augusto C. Miranda ${ }^{10}$, Marcello Delano Bronstein', Antônio Ribeiro-Oliveira Jr. ${ }^{11}$

\begin{abstract}
Although it is a rare condition, the accurate diagnosis and treatment of Cushing's disease is important due to its higher morbidity and mortality compared to the general population, which is attributed to cardiovascular diseases, diabetes mellitus and infections. Screening for hypercortisolism is recommended for patients who present multiple and progressive clinical signs and symptoms, especially those who are considered to be more specific to Cushing's syndrome, abnormal findings relative to age (e.g., spinal osteoporosis and high blood pressure in young patients), weight gain associated with reduced growth rate in the pediatric population and for those with adrenal incidentalomas. Routine screening is not recommended for other groups of patients, such as those with obesity or diabetes mellitus. Magnetic resonance imaging (MRI) of the pituitary, the corticotropin-releasing hormone $(\mathrm{CRH})$ test and the high-dose dexamethasone suppression test are the main tests for the differential diagnosis of ACTH-dependent Cushing's syndrome. Bilateral and simultaneous petrosal sinus sampling is the gold standard method and is performed when the triad of initial tests is inconclusive, doubtful or conflicting. The aim of this article is to provide information on the early detection and establishment of a proper diagnosis of Cushing's disease, recommending follow-up of these patients at experienced referral centers. Arch Endocrinol Metab. 2016;60(3):267-86
\end{abstract}

Keywords

Cushing's disease; Cushing's syndrome; diagnosis

\section{INTRODUCTION}

$\mathrm{E}$ ndogenous Cushing's syndrome can be defined as a condition resulting from prolonged and inappropriate exposure to excessive amounts of cortisol, partial loss of the normal counter-regulation of the hypothalamic-pituitary-adrenal axis and loss of circadian rhythm in cortisol secretion (1).

Cushing's disease (CD) is a rare clinical condition that is due to ACTH-producing pituitary adenoma, and it is the most common etiology of endogenous Cushing's syndrome after 6 yrs of age $(\sim 70 \%)(2)$.

CD has an estimated incidence of 2-3 cases per 1.000.000 inhabitants/year and a prevalence of approximately 40 cases per 1.000 .000 inhabitants (3), occurring mainly in women $(3-8: 1)(3,4)$. It can affect individuals at any age, but it is most prevalent in the second and third decades of life and is mostly $(\sim 80-90 \%)$ caused by pituitary tumors with a diameter less than $10 \mathrm{~mm}$ (microadenomas) (5-7).

ACTH-secreting pituitary adenomas are sporadic tumors in the vast majority of cases, but they can rarely be part of genetic conditions such as multiple endocrine neoplasia type 1 (NEMl), multiple endocrine neoplasia type 4 (NEM4) and fami-
1 Unidade de Neuroendocrinologia, Serviço de Endocrinologia e Metabologia, Hospital das Clínicas da Faculdade de Medicina da Universidade de São Paulo (HCFMUSP); Departamento de Endocrinologia, A.C. Camargo Cancer Center, São Paulo, SP, Brasil; ${ }^{2}$ Divisão de Endocrinologia e Metabologia, Faculdade de Medicina de Ribeirão Preto, Universidade de São Paulo (FMRPUSP), Ribeirão Preto, SP, Brasil; ${ }^{3}$ Serviço de Endocrinologia e Metabologia (SEMPR), Hospital de Clínicas, Universidade Federal do Paraná (UFPR), Curitiba, PR, Brasil; ${ }^{4}$ Serviço de Endocrinologia, Hospital Universitário Clementino Fraga Filho, Universidade Federal do Rio de Janeiro (HUCFF/ UFRJ), Rio de Janeiro, RJ, Brasil; ${ }^{5}$ Serviço de Endocrinologia, Hospital Universitário de Brasília Universidade de Brasília (UnB), Brasília, DF, Brasil; ${ }^{6}$ Serviço de Endocrinologia, Hospital de Clínicas, Universidade Federal de Pernambuco (UFPE), Recife, PE, Brasil; ${ }^{7}$ Endoville, Joinville, SC Brasil; ${ }^{8}$ Serviço de Endocrinologia, Hospital de Clínicas de Porto Alegre (HCPA), Faculdade de Medicina da Universidade Federal do Rio Grande do Sul (UFRGS), Porto Alegre, RS, Brasil; 9 Unidade de Neuroendocrinologia, Divisão de Neurocirurgia Funcional, Hospital das Clínicas da Faculdade de Medicina da Universidade de São Paulo (HCFMUSP), São Paulo, SP:

${ }^{10}$ Serviço de Endocrinologia, Santa Casa de Belo Horizonte,

Belo Horizonte, MG, Brasil;

"Serviço de Endocrinologia,

Hospital de Clínicas, Universidade Federal de Minas Gerais (UFMG), Belo Horizonte, MG, Brasil

Correspondence to: Antônio Ribeiro-Oliveira Jr. Av. Alfredo Balena, 110 Serviço de Endocrinologia, Hospital de Clínicas,

Universidade Federal de Minas Gerais 30130-100 - Belo Horizonte, MG, Brasil

antoniorojr@gmail.com

Received on Feb/5/2016 Accepted on Mar/10/2016 DOI: 10.1590/2359-3997000000174 
lial isolated pituitary adenoma (FIPA) (8). Other less common etiologies of endogenous Cushing's syndrome include ectopic ACTH secretion (EAS 10\%), adrenal adenomas and carcinomas and, more rarely, adrenal primary macronodular adrenal hyperplasia (PMAH) or primary pigmented nodular adrenal disease (PPNAD) (Table 1). In children under 5 years of age, adrenal causes (ACTH-independent: adrenal adenoma and carcinoma) are the most common, whereas bilateral adrenal hyperplasia due to McCune-Albright syndrome is the most common cause in the first year of life. CD is the most prevalent etiology $(75 \%)$ in patients older than 7 years (2).

Table 1. Etiologies of endogenous Cushing's syndrome

\begin{tabular}{lc}
\hline Cushing's syndrome etiology $^{\star}$ & Prevalence $^{\star \star}$ \\
\hline ACTH-dependent Cushing's syndrome & $\mathbf{8 0} \%$ \\
Cushing's disease & $70 \%$ \\
Ectopic ACTH syndrome & $10 \%$ \\
Ectopic CRH secretion & $<1 \%$ \\
Carcinoma corticotropic & Rare \\
Ectopic CRH/ACTH secretion & Rare \\
ACTH-independent Cushing's syndrome & $\mathbf{2 0 \%}$ \\
Adrenal adenoma & $10 \%$ \\
Adrenal carcinoma & $5 \%$ \\
Primary macronodular adrenal hyperplasia (PMAH) & $<2 \%$ \\
Primary pigmented nodular adrenocortical disease (PPNAD) & $<2 \%$ \\
McCune-Albright syndrome & Rare \\
Ectopic cortisol secretion & Rare \\
Cortisol hypersensitivity & Rare \\
\hline
\end{tabular}

* References: 4,49,117,182; ** Prevalence in adult patients.

Patients with Cushing's syndrome have a higher mortality than the general population (9-21), mainly due to the development of cardiovascular disease (ischemic heart disease and cerebrovascular disease), diabetes mellitus (secondary to hypercortisolism) and infections (due to the state of immunosuppression).

A meta-analysis showed a standardized mortality ratio (SMR) of 2.22 (1.45-3.41; confidence interval 95\%) (15), which varied between studies from 0.98 (0.44-2.18) (10) to 4.80 (2.79 to 8.27) (15). However, when analyzing the mortality rate in relation to the remission of Cushing's syndrome, there was a higher mortality rate in patients with persistent disease compared to those in clinical remission: 5.50 (2.69-11.26) vs. $1.20(0.45-3.18)$, respectively (15).

Another factor that contributes to the onset and progression of the associated comorbidities is the diffi- culty in identifying patients with a subtler clinical picture, which delays the diagnosis of Cushing's syndrome and its etiology. Some studies have shown that this time can vary from 2-5 years from the initial consultation to the end of investigation $(9,22-25)$, and the longer exposure to hypercortisolism has been proved to be an independent factor associated with higher mortality in patients with Cushing's syndrome (17).

Thus, to improve the prognosis of patients with Cushing's syndrome and to enhance the reversibility of comorbidities, an early recognition of the disease and the reversal of hypercortisolism to eucortisolism are essential. Eventually, very severe hypercortisolism may present as a medical emergency with very high mortality if not promptly treated. The diagnosis of these patients must be made expeditiously, and treatment must be started immediately (1).

The aim of this article is to provide information on the early detection and establishment of a proper diagnosis of $\mathrm{CD}$. We recommend monitoring these patients in centers with experienced multidisciplinary teams (endocrinologists, neurosurgeons, radiologists, radio-interventionists) to establish the diagnosis, to indicate the best treatment and to conduct follow-ups of these patients.

\section{DIAGNOSIS OF ENDOGENOUS CUSHING'S SYNDROME}

\section{Who should we investigate for Cushing's syndrome?}

The classic clinical features of Cushing's syndrome consist of weight gain causing overweight or obesity with an abdominal and truncal distribution, fatigue, menstrual abnormalities such as oligomenorrhea or amenorrhea, reduced libido and/or erectile dysfunction, decreased growth rate associated with weight gain in children, and psychiatric disturbances including depression, decreased concentration and memory, irritability and insomnia.

Physical examinations can show a wide variability of features related to Cushing's syndrome, ranging from subtle to overt features. In patients who present with overt Cushing's syndrome, we can observe plethoric round face ("moon face"), dorsal hump ("buffalo hump"), filled supraclavicular fossa, skin atrophy, acne, hirsutism, hair loss, and peripheral edema. In children, a short stature, abnormal virilization, pubertal delay or pseudo precocious puberty may be observed. Moreover, there are common comorbidities in clinical prac- 
tice, such as hypertension, diabetes mellitus, nephrolithiasis, osteopenia or osteoporosis, hypokalemia, and unusual fungal infections. However, all of these signs, symptoms and morbidities are non-specific, as they may be present in metabolic syndrome, severe diabetes mellitus, polycystic ovary syndrome, grade III obesity, depression and chronic alcoholism (26). Thus, it is important to look for more specific signs of Cushing's syndrome, such as facial plethora, proximal muscle weakness, large $(>1 \mathrm{~cm})$ and reddish/violet skin striae and spontaneous ecchymosis in patients presenting weight gain $(27,28)$ (Table 2$)$.

Table 2. Prevalence of symptoms, signs and morbidities of Cushing's syndrome

\begin{tabular}{|c|c|}
\hline Symptoms, signs and morbidities* & Prevalence \% \\
\hline Weight gain or obesity/abdominal obesity & 95 \\
\hline Facial plethora & 90 \\
\hline Facial fullness & 90 \\
\hline Decreased libido/erectile dysfunction & 90 \\
\hline Thin skin & 85 \\
\hline Menstrual abnormalities/amenorrhea & 80 \\
\hline Decreasing growth velocity ${ }^{\star \star}$ & $70-80$ \\
\hline Arterial hypertension & 75 \\
\hline Hirsutism & 75 \\
\hline Depression/emotional lability & 70 \\
\hline Dyslipidemia & 70 \\
\hline Striae (especially if red or purple and more than $10 \mathrm{~mm}$ wide) & $70-90$ \\
\hline Dorsocervical fat pad/supraclavicular fullness & $50-70$ \\
\hline Easy bruising & 65 \\
\hline Impaired glucose-tolerance/diabetes mellitus & 60 \\
\hline Proximal myopathy/weakness & 60 \\
\hline Osteopenia or osteoporosis/fracture & 50 \\
\hline Kidney stones & 50 \\
\hline Exophthalmos & 45 \\
\hline Polyuria & 30 \\
\hline Headache & $20-50$ \\
\hline Back pain & $20-50$ \\
\hline Peripheral edema & $20-50$ \\
\hline Unusual infections/fungal infections & $20-50$ \\
\hline Hypokalemia & $10-70$ \\
\hline Acne & $<20$ \\
\hline Alopecia/female balding & $<20$ \\
\hline Hyperpigmentation & 10 \\
\hline
\end{tabular}

* References: 1,27,49,119,183,184; ** Prevalence in pediatric patients (184).

In contrast, patients suffering from Cushing's syndrome due to EAS, particularly those with malignancies such as small cell lung carcinoma, may have an atypical clinical presentation, with a predomination of consumptive state $(35 \%)$, higher frequency of hypokalemia (> 70\%), hyperpigmentation, osteopenia/osteoporosis and metabolic disorders, such as glucose intolerance (29).

Thus, it is recommended to investigate Cushing's syndrome in patients who have multiple and progressive signs and symptoms, especially those considered more specific, such as the presence of spinal osteoporosis and hypertension, weight gain in children coupled with a reduction in growth, and the finding of adrenal incidentalomas. Routine investigation is not otherwise recommended for other groups of patients, such as those with isolated obesity or hirsutism $(27,30,31)$ (Table 3$)$.

Table 3. Recommendations for Cushing's syndrome screening

\begin{tabular}{l}
\hline Cushing's syndrome screening* \\
\hline Presence of multiple and progressive features, especially those more specific \\
to Cushing's ${ }^{\star *}$ \\
Unusual features for age (vertebral osteoporosis, arterial hypertension) \\
Pediatric patients with decreasing growth velocity/short stature and weight \\
gain \\
Adrenal incidentaloma \\
We do not recommend widespread screening for Cushing's syndrome in other \\
clinical situations (e.g., obesity, diabetes mellitus, hirsutism) without the \\
presence of more specific features of hypercortisolism
\end{tabular}

* References: 27,30,31; ${ }^{* \star}$ Easy bruising, facial plethora, proximal myopathy/weakness, striae (especially if red or purple and more than $1 \mathrm{~cm}$ wide).

However, several studies have been devoted to investigating hypercortisolism in groups of patients considered at risk or in whom the prevalence of Cushing's syndrome may be greater than expected. The at-risk conditions often highlighted are secondary hypertension, in which the prevalence of Cushing's syndrome has been reported to be approximately $0.5-1 \%$ of cases, adrenal incidentalomas (6-9\%) and unexplained osteoporosis with vertebral fracture (11\%) $(32,33)$.

However, the most studied risk condition is diabetes mellitus, which was found to have a prevalence of $0.8 \%(0-3.3 \%)$ in a group of 2,381 diabetic patients from 12 studies (34-45). Striking Cushing's features have not been described in diabetic patients with an HbAlc between 8.4-12.2\% associated with hypertension and overweight/obesity (BMI between 25.4$34.5 \mathrm{~kg} / \mathrm{m}^{2}$ ). Additionally, other factors such as the lack of knowledge of the natural history of this "occult" Cushing's syndrome and questions regarding the best therapeutic strategy (identification and treatment of Cushing's syndrome vs. treatment of diabetes melli- 
tus) preclude a recommendation for routine screening of Cushing's syndrome in patients with diabetes mellitus (46).

Finally, although there is no indication of the need to screen for Cushing's syndrome in either overweight or obesity patients without other suggestive features (27-30), one study showed a prevalence of $0.8 \%$ of Cushing's syndrome in 783 obese preoperative patients undergoing bariatric surgery (47). Interestingly, obese patients usually show a normal circadian rhythm of salivary cortisol (48).

\section{First-line tests}

After clinical suspicion and thorough exhaustive exclusion of exogenous sources of glucocorticoids of any kind, such as oral, injected, topical or inhaled steroids, the diagnosis of Cushing's syndrome has two sequential steps. The first step consists of tests to confirm hypercortisolism associated with loss of normal circadian rhythm of cortisol secretion and the relative autonomy of cortisol production, independent of the etiology of Cushing's syndrome. It is noteworthy that at least two distinct methods must be abnormal to diagnose Cushing's syndrome. Altered findings from only one method may be present in cases of pseudoCushing's.

In a subsequent step, which is usually performed at referral centers, the establishment of the differential diagnosis of ACTH-dependent or independent Cushing's syndrome should be conducted (49).
The diagnosis of Cushing's syndrome is very much dependent on cortisol tests, which vary substantially depending on the utilized assay. Therefore, clinicians involved in this diagnosis should be aware of their institutional assays before adhering to the strict cut-offs suggested by the literature.

\section{Low-dose dexamethasone suppression test}

The low-dose dexamethasone suppression test (LDT) constitutes one of the main methods used for screening, and it evaluates for a lack of negative feedback of cortisol on the hypothalamic-pituitary-adrenal axis. This test should be performed after an overnight oral intake (between 11:00 pm and 12:00 am) of $\mathrm{l} \mathrm{mg}$ dexamethasone, and blood collection for measurement of serum cortisol should occur in the subsequent morning between 8:00 am and 9:00 am. Cortisol values above $1.8 \mu \mathrm{g} / \mathrm{dL}(50 \mathrm{nmol} / \mathrm{L})$ are considered abnormal, with a sensitivity higher than $95 \%$ and an $80 \%$ specificity (27) (Table 4 ).

Previously, the cutoff value was higher than $5 \mu \mathrm{g} / \mathrm{dL}$ ( $140 \mathrm{nmol} / \mathrm{L})$, which is still currently used by some authors in some specific clinical situations (e.g., adrenal incidentalomas). However, although this criterion increases the specificity of the method (50), the present approach is more adequate and sensitive because it is known that $18 \%$ of patients with Cushing's syndrome have suppressed values below $5 \mu \mathrm{g} / \mathrm{dL}$, and up to $8 \%$ of patients with Cushing's syndrome have suppressed serum cortisol below $1.8 \mu \mathrm{g} / \mathrm{dL}$ with $1 \mathrm{mg}$ dexamethasone (51).

Table 4. Laboratory methods for Cushing's syndrome diagnosis

\begin{tabular}{|c|c|c|c|}
\hline Method & Reference value & Sensitivity \% & Specificity \% \\
\hline \multicolumn{4}{|l|}{ First-line methods } \\
\hline Low-dose dexamethasone suppression test - $1 \mathrm{mg}$ overnight (serum cortisol) (27) & $>1.8 \mu \mathrm{g} / \mathrm{dL}$ & $>95$ & 80 \\
\hline $\begin{array}{l}\text { Longer low-dose dexamethasone suppression test - } 2 \text { mg/day for } 48 \mathrm{~h}-0.5 \mathrm{mg} 6 / 6 \mathrm{~h} \text { (serum } \\
\text { cortisol) }(68)^{*}\end{array}$ & $>1.8 \mu \mathrm{g} / \mathrm{dL}$ & $92-100$ & $92-100$ \\
\hline Late night salivary cortisol ( $\mu \mathrm{g} / \mathrm{dL}$ or $\mathrm{ng} / \mathrm{dL}$ or mmol/L) (56) & $>2 X$ ULNR & $88-100$ & $82-100$ \\
\hline Urinary free cortisol 24 h ( $\mu \mathrm{g} / 24$ h) (68) & $>3-4 X$ ULNR & $90-98$ & $45-95$ \\
\hline \multicolumn{4}{|l|}{ Other methods (second-line) } \\
\hline Late-night serum cortisol (patient awake) (78) & $>7.5 \mu \mathrm{g} / \mathrm{dL}$ & 96 & 100 \\
\hline Ovine CRH after longer low-dose dexamethasone suppression test (serum cortisol) (81-84) & $>1.4 \mu \mathrm{g} / \mathrm{dL}\left(15^{\prime}\right)$ & $<100$ & $<100$ \\
\hline Human CRH test (plasma ACTH, pg/mL; serum cortisol, $\mu \mathrm{g} / \mathrm{dL}$ ) (86) & $\begin{array}{c}\text { Peak }>54 \mathrm{pg} / \mathrm{mL} \\
\text { and }>12 \mu \mathrm{g} / \mathrm{dL} \\
\text { (baseline) }\end{array}$ & 91.3 & 98.2 \\
\hline Desmopressin test (plasma ACTH, pg/mL; serum cortisol, $\mu \mathrm{g} / \mathrm{dL}$ ) (90) & $\begin{array}{c}\Delta>18 \mathrm{pg} / \mathrm{mL} \text { and }> \\
12 \mu \mathrm{g} / \mathrm{dL} \text { (baseline) }\end{array}$ & $86.6-100$ & 92.8 \\
\hline
\end{tabular}

$\triangle$ : delta: peak less baseline value; ULNR: upper limit of normal range; * Meta-analysis showed a similar or lower accuracy than that of the low-dose dexamethasone suppression test (1 mg overnight) (54); serum cortisol: $\mu \mathrm{g} / \mathrm{dL}$; to nmol/L, multiply by $27.59 ; \mathrm{ACTH}: \mathrm{pg} / \mathrm{mL}$; to pmol/L, multiply by 0.2202 ; urinary cortisol: $\mu \mathrm{g} / 24 \mathrm{~h}$; to $\mathrm{nmol} / 24 \mathrm{~h}$, multiply by 2.759 . 
False positives can occur in states of hyperactivation of the hypothalamic-pituitary adrenal axis (pseudo-Cushing's state, such as depression and alcoholism) and in conditions increasing cortisol-binding globulin (CBG) such as estrogen treatment, which accounts for up to $50 \%$ of the false positives and requires interruption for at least 6 weeks before the test. Other false positive results may occur due to pregnancy, mitotane use, malabsorption of medication or conditions that increase the metabolism of dexamethasone due to activation of the enzyme CYP3A4 (phenytoin, phenobarbital, rifampin, carbamazepine, pioglitazone, topiramate etc.) (Table 5). False negatives can occur in "mild" Cushing's syndrome and with the use of drugs that reduce the action of the enzyme CYP3A4 (fluoxetine, cimetidine, itraconazole, ritonavir, diltiazem, and amiodarone, among others). Moreover, even drugs that are not traditionally known for changes in the metabolism of dexamethasone may do so as a result of an interaction with other drugs. A complete list of medications can be found on the following site: http://medicine. iupui.edu/flockhart/table.htm.

Likewise, a recent study assessing the influence of the use of several concomitant medications on oCRH stimulation after longer low-dose dexamethasone suppression tests confirmed a low accuracy of the method in patients receiving those medications (52).

As a result, serum dexamethasone concentrations (1 mg overnight: $>140-220 \mathrm{ng} / \mathrm{mL})(27,30)$ that are measured at the same time as serum cortisol can rule out possible confounding factors, increasing the reliability of the method. However, the measurement of dexamethasone is rarely available in our country.

There is no evidence that the use of higher doses of overnight dexamethasone ( 1.5 or $2 \mathrm{mg}$ ) increases the accuracy of the method. Furthermore, the same procedure used in the adult population has been applied to pediatric populations, with the only change being a dose adjustment $(15-20 \mu \mathrm{g} / \mathrm{kg})$ for patients weighing less than $40 \mathrm{~kg}(2,53)$.

Alternatively, some authors prefer a low-dose dexamethasone test using fractionated doses rather than $1 \mathrm{mg}$ overnight to increase the specificity of the method in states of hyperactivation of the hypothalamic-pituitary-adrenal axis, such as depression, alcoholism or even uncontrolled diabetes mellitus. In such cases, 0.5 $\mathrm{mg}$ of dexamethasone is administered every 6 hours for two days ( 8 doses), most commonly beginning with the first dose on the first day at 9:00 am and the last dose
Table 5. Drugs that may interfere with the evaluation of dexamethasone suppression tests

\begin{tabular}{l}
\hline Drugs that accelerate dexamethasone metabolism - induction of CYP \\
3A4 - potential false positive LDT \\
\hline Carbamazepine \\
Ethosuximide \\
Phenytoin \\
Phenobarbital \\
Pioglitazone \\
Primidone \\
Rifampicin \\
Rifapentine \\
\hline Drugs that impair dexamethasone metabolism - inhibition of CYP 3A4 \\
- potential false negative LDT \\
\hline Amiodarone \\
Aprepitant/fosaprepitant \\
Cimetidine \\
Ciprofloxacin/norfloxacin \\
Diltiazem \\
Fluoxetine \\
Itraconazole/fluconazole \\
Ritonavir/indinavir/nelfinavir \\
\hline
\end{tabular}

LDT: low-dose dexamethasone suppression test. Reference: 27 . More complete data available on the following site: http://medicine.iupui.edu/flockhart/table.htm.

occurring at 3:00 am on the last day (6 hours before blood collection at 9:00 am) or with the first dose at lunch $(12: 00 \mathrm{pm})$ on the first day and the last dose at 6:00 am on the last day (two hours before cortisol collection). Conceived by Liddle in the 1960s and using cortisol metabolite in the urine (17OHCS), the same criterion of a serum cortisol response $>1.8 \mu \mathrm{g} / \mathrm{dL}$ is currently adopted. The non-fractionated $1 \mathrm{mg}$ test is preferable to the 48 -h fractionated one because the latter is labor intensive and more error-prone and has shown a diagnostic accuracy slightly lower than that of the overnight test in an important meta-analysis (54).

Thus, rather than choosing the form of dexamethasone administration, it is important to emphasize that at this stage of diagnosis, a greater sensitivity of the methods should be prioritized and, especially in cases of mild Cushing's, the complementarity and agreement of different methods will confirm the diagnosis, as just one abnormal result does not confirm the diagnosis of the syndrome.

\section{Late-night salivary cortisol}

Late-night salivary cortisol is an important method in the diagnostic evaluation of Cushing's syndrome. 
It should be ordered whenever available, especially in centers with an established methodology and cutoff values that have been studied in different populations (normal, obese/pseudo-Cushing's and Cushing's syndrome), with a sensitivity of $88-100 \%$ and specificity of $82-100 \%(55,56)$ for adults, and of 95.2 and $100 \%$, respectively, for children (53).

An above normal value on this test reflects the lack of a normal circadian rhythm of cortisol secretion, which is considered one of the first events to occur in Cushing's syndrome. Therefore, some authors have advocated using this test as a first method of screening $(33,56-58)$.

In a study of 11 cases of mild Cushing's that had a difficult diagnosis, the measurement of late-night salivary cortisol proved to be persistently altered in most patients, while most of the urinary cortisol samples remained within the normal range (59). Another recent study found a higher diagnostic accuracy of nocturnal salivary cortisol when compared to urinary cortisol in 52 patients with Cushing's syndrome (60).

Salivary cortisol is an analysis method that assesses free cortisol, in dynamic equilibrium with serum cortisol, reflecting a percentage of total serum cortisol $(65 \%)$, and it is not influenced by saliva flow (61). There are several advantages of this method, such as the non-invasiveness of its collection and the sample stability at room temperature (either one week at room temperature or a few weeks if refrigerated).

Salivary cortisol can be collected in two ways: passive collection (best for small children) or through a commercial collector (Salivette ${ }^{\circledR}$ ) between 11:00 pm and 12:00 am. It is recommended to collect at least two samples on consecutive or alternate days (62). Salivary cortisol concentrations are commonly determined by radioimmunoassay, ELISA, and automated electrochemiluminescence $(62,63)$; more recently, liquid chromatography/mass spectrometry has also been utilized (30,64-66).

It must be emphasized that a significant conversion of cortisol to cortisone occurs in the salivary glands by the action of $11 \beta$-hydroxysteroid dehydrogenase II enzyme (11 $\beta$-HSD2), leading to a higher concentration of cortisone than cortisol in the saliva. This fact could explain the finding of the same $(92 \%)$ or even lower $(74.5 \%)$ sensitivity with equal specificity (90-92\%) of salivary cortisol by liquid chromatography/mass spectrometry (LC-MS/MS) in diagnosing Cushing's syndrome (64-65) compared with the sensitivity and specificity of conventional immunoassays using anticortisol antibodies, showing cross-reactivity with cortisone $(55,67)$. The use of LC-MS/MS can be particularly useful in cases of saliva contamination with synthetic steroids (67).

Because different studies have used different cutoff values with different methods, there is no cutoff value for salivary cortisol that can be widely recommended, unlike the interpretation of serum cortisol after low-dose dexamethasone. Late-night salivary cortisol values more than twice the upper limit have been found to increase the specificity of the method in diagnosing hypercortisolism (67). A review found a mean late-night salivary cortisol level of $250 \pm 104 \mathrm{ng} / \mathrm{dL}$ (130$415 \mathrm{ng} / \mathrm{dL}$ ) in patients with Cushing's syndrome (68).

As with any method, false negatives and most especially false positives can occur in individuals with an altered sleep-wake cycle, psychiatric disorders, uncontrolled diabetes mellitus, and oral/gum disease (blood contamination) and in the elderly $(27,37,55)$; additionally, extremely high results can be due to contamination with corticosteroids in skin creams (57). In addition, it is recommended not to smoke $24 \mathrm{~h}$ before collection due to glycyrrhizic acid (derived from licorice), which inhibits the $11 \beta$-HSD2 salivary enzyme.

Finally, there have been studies on using morning salivary cortisol levels after an overnight ingestion of $1 \mathrm{mg}$ dexamethasone rather than a traditional serum cortisol test $(37,69,70)$. Given the ease, convenience and noninvasive method of its collection, this may be an alternative to initial screening as it easily comprises two screening methods (late-night salivary cortisol from the previous night and subsequent salivary cortisol after dexamethasone suppression). However, to implement a method of salivary cortisol after dexamethasone suppression, the cross-reactivity of dexamethasone and salivary cortisol should be first ruled out for the chosen assay.

\section{4-h urinary cortisol}

The measurement of free cortisol in 24-h urine samples (24-h UFC) as well as serum cortisol suppression tests after low-dose dexamethasone are the traditional diagnostic methods used for the diagnosis and monitoring of patients with Cushing's syndrome. The 24-h UFC measurement reflects the integrated daily production of cortisol, which is almost always elevated in hypercortisolism. 
At least two samples of 24-h UFC, consecutive or alternate, must be requested to exclude false negatives due to variations in cortisol secretion, and 24-h UFC should always be evaluated together with a 24 -h creatinine ratio to confirm the adequacy of the sample.

One study found at least one normal sample of 24-h UFC out of four samples in $11 \%$ of patients with hypercortisolism (71), and other recent studies have shown a variation of $31-52 \%$ in urinary cortisol concentrations in 3-4 samples obtained from the same patients at diagnosis $(60,72)$. Each sample must be collected for $24 \mathrm{~h}$, discarding the first urine sample and including the first urine of the morning the subsequent day. The sample must be kept refrigerated until it is delivered to the laboratory.

False positives can occur in states of pseudoCushing's, such as depression, alcoholism, obesity, pregnancy, and polyuria (example: patients with diabetes insipidus), by the interference of certain drugs (carbamazepine, fenofibrate, digoxin, some synthetic corticosteroids) and other substances that inhibit the 11 $\beta$-HSD2 enzyme (licorice, carbenoxolone). However, in these cases, the 24-h UFC concentrations are usually less than 1.5-2 times above the upper limit of the method. False negatives may occur in patients with renal insufficiency (creatinine clearance less than $60 \mathrm{~mL} /$ minute), mainly due to an inadequate collection of urine (27).

In addition, slightly elevated or normal samples also occur in mild Cushing's syndrome, adrenal incidentalomas, cyclic Cushing's syndrome and ACTH-secreting macroadenomas. Currently, considering the data from the three first-line methods, urinary cortisol has been less valued than the others as a screening test for the diagnosis of Cushing's syndrome $(67,73)$. Likely, a slight increase in cortisol production in the circadian nadir may not be detected as an increase in 24-h UFC. Nevertheless, it remains an important method when used in combination with other diagnostic methods, although it is especially valued and more specific when the observed result is 3-4 times greater than the upper limit of the method.

It is noteworthy to mention that the same reference values for adults can be used in children over $45 \mathrm{~kg}$, with a sensitivity of approximately $89 \%(74,75)$.

In general, 24-h UFC does not experience interference from conditions that increase corticosteroidbinding globulin (CBG). There are several methods used to measure 24-h UFC, in particular immunoas- says with upper limits of approximately $90-120 \mu \mathrm{g} / 24 \mathrm{~h}$. Recently, and similarly to other steroids, more specific methods have been used, such as high performance liquid chromatography (HPLC) and mass spectrometry, with upper limits typically ranging from approximately 40 to $60 \mu \mathrm{g} / 24 \mathrm{~h}$. One study showed differences in the value of 24-h UFC in relation to gender, with slightly higher values in women (76), while other studies have found the opposite (77).

\section{Additional tests or second-line tests}

Second-line tests are indicated when diagnostic uncertainty persists after the completion of first-line tests. This is particularly true for cases of mild Cushing's syndrome in which the complementarity and correlation of different methods is necessary for a confirmed diagnosis of hypercortisolism (54).

\section{Late-night serum cortisol}

Although it is an older method and has the same rationale as the nocturnal salivary cortisol test, late-night serum cortisol is considered a second-line examination because it requires the hospitalization of the patient for sample collection at least 48 hours after admission, between 11:00 pm and 12:00 am.

Several studies have analyzed this method, but with different control groups, different collection methods (patient asleep or awake) and with different cutoff values. The most commonly used cutoff value in the literature originates from a 1998 study indicating that a cortisol value higher than $7.5 \mu \mathrm{g} / \mathrm{dL}$ is suggestive of Cushing's syndrome (patient at rest, but awake) with $96 \%$ sensitivity and $100 \%$ specificity (78).

A previous study performed collection in sleeping patients (with previously installed venous access) and found a cortisol value higher than $1.8 \mu \mathrm{g} / \mathrm{dL}$ as suggestive of Cushing's syndrome with $100 \%$ sensitivity (79). However, because collection is not always easy in a sleeping patient and the cutoff was very low, other studies have not replicated these data with enough specificity (80). Due to the increased availability and the advantages of late-night salivary cortisol over latenight serum cortisol, the latter is currently seldom used.

Alternatively, and with the same goal, serum cortisol at 4:00 pm has also been analyzed. However, there is a substantial overlap in cortisol values between patients with or without Cushing's syndrome, preventing an accurate interpretation of the serum cortisol collected at this time point. 


\section{Ovine CRH stimulation after longer low-dose dexamethasone suppression test}

Also known as the Yanovski test, the ovine CRH test was published in 1993 (81). It is still considered by some authors as the best method for the differential diagnosis between Cushing's syndrome and states of pseudo-Cushing's. It is performed with $0.5 \mathrm{mg}$ dexamethasone suppression for two days ( 8 doses) with the last dose at 6:00 am. Then, after two hours, there is an IV infusion of $1 \mu \mathrm{g} / \mathrm{kg}$ or $100 \mu \mathrm{g}$ of ovine CRH (oCRH). A serum cortisol value higher than $1.4 \mu \mathrm{g} / \mathrm{dL}$ (absolute value) after 15 minutes is considered positive and suggestive of Cushing's syndrome. In the original publication, this method showed 100\% accuracy, an exceptional result, although this has not been reproduced by others $(52,82-84)$. Furthermore, due to the high cost and unavailability of ovine $\mathrm{CRH}$, its use is currently limited. Therefore, we do not recommend this poorly characterized, expensive and complex test.

\section{Human CRH test}

Traditionally used for the differential diagnosis of ACTH-dependent Cushing's syndrome (85), the human CRH (hCRH) test was studied in 2009 to differentiate Cushing's syndrome from states of pseudo-Cushing's (86). Using statistical analysis to obtain maximum accuracy, the best criterion found has been a serum cortisol value higher than $12 \mu \mathrm{g} / \mathrm{dL}$ at baseline (absolute value, mean time - 15 and $0 \mathrm{~min}$ ) and peak ACTH higher than $54 \mathrm{pg} / \mathrm{mL}$ (absolute value) after a $100 \mu \mathrm{g} \mathrm{IV}$ infusion of hCRH, with a sensitivity of $91.3 \%$ and specificity of $98.2 \%$ for $\mathrm{CD}$, which was better than both firstline methods and nocturnal serum cortisol. However, as with oCRH, due to the high cost and unavailability of the product in Brazil, its use is still currently limited.

\section{Desmopressin test}

Desmopressin has been used for the differential diagnosis of ACTH-dependent Cushing's syndrome since 1993 (87). Moreover, it has also been studied with the aim of differentiating Cushing's syndrome from states of pseudo-Cushing's (88).

However, as of 2000 , the desmopressin test $(10 \mu \mathrm{g}$ IV) showed no significant accuracy in ruling out pseudo-Cushing's states due to a frequent response (> 50\%) in normal subjects when using percentage increases in both ACTH and cortisol as the response criteria (89). In 2007, a study showed equal accuracy between the desmopressin and Yanovski test, but it used the criteria of an ACTH $\Delta>27 \mathrm{pg} / \mathrm{mL}$ after desmopressin (84 vs. $85 \%$, respectively) (50).

Similar to the hCRH test previously reported (86), the same group published a new reassessment of the desmopressin test after an intensive statistical analysis in 2010, finding new response criteria: serum cortisol higher than $12 \mu \mathrm{g} / \mathrm{dL}$ at baseline (mean between -15 and $0 \mathrm{~min}$ ) and an ACTH increase of $>18 \mathrm{pg} / \mathrm{mL}$ (peak until $30 \mathrm{~min}$ minus the baseline value). Using this criteria, a sensitivity of $86.6-100 \%$ and a specificity of $92.8 \%$ was found, higher than that of the previous criteria of $\Delta>27 \mathrm{pg} / \mathrm{mL}$ and again better than the use of increase-percentage values in both ACTH and cortisol. Importantly, this study provided a differential diagnosis of mild Cushing's syndrome vs. pseudo-Cushing's, providing an advantage when compared to first-line methods and the late-night serum cortisol test (90).

In 2011, one study compared the hCRH with the desmopressin test using the new criteria and verified the identical and excellent performance of both tests in the differential diagnosis of ACTH-dependent Cushing's syndrome and states of pseudo-Cushing's, with a $96.6 \%$ sensitivity and $100 \%$ specificity for both tests (91), results even better than both first-line methods and nocturnal serum cortisol.

Finally, a recent study in patients with CD $(n=68)$ and patients with pseudo-Cushing's $(n=56)$ demonstrated by ROC curves the use of a peak ACTH value of $71.8 \mathrm{pg} / \mathrm{mL}$ after desmopressin, showing a $94.6 \%$ specificity, $90.8 \%$ sensitivity, $89.8 \%$ negative predictive value (NPV) and $95.3 \%$ positive predictive value (PPV) for the diagnosis of CD. In the same study, an increase of ACTH equal to or greater than $37 \mathrm{pg} / \mathrm{mL}$ after desmopressin showed $88 \%$ sensitivity, $96.4 \%$ specificity, $87 \%$ NPV and 95.3\% PPV also for the diagnosis of CD (92).

Therefore, the desmopressin test seems to be a good method for the differential diagnosis of ACTHdependent Cushing's syndrome and states of pseudoCushing's. Due to the greater availability and lower cost of desmopressin, it should be further studied.

\section{Special situations}

\section{Pregnancy}

The diagnosis of Cushing's syndrome, though rarely concomitant with pregnancy $(93,94)$, presents unique difficulties. Adrenal adenoma is the most common etio- 
logy, accounting for $46 \%$ of Cushing's syndrome cases in pregnancy $(93,94)$. It is also occasionally a cause of pseudo-Cushing's $(95,96)$.

False positive results commonly occur with low-dose dexamethasone suppression tests in pregnancy due to a secondary CBG increase related to estrogen levels during pregnancy as well as the attenuation of axis suppression in pregnancy $(93,94)$. Regarding 24-h UFC, although not influenced by CBG increase, an important physiological increase in urinary cortisol concentrations in the second and third trimesters has been shown, which can reach up to three times the upper limit of the method (97). Thus, only concentrations higher than 3-4 times the upper limit of the method can be useful for diagnosis.

Typically, the circadian rhythm of cortisol secretion is maintained during gestation and should theoretically be explored for diagnosis. However, there are no specific studies that define cutoff values for late-night serum cortisol during pregnancy, and there are only two studies that assess late-night salivary cortisol with a small group of pregnant women $(98,99)$. Therefore, studies are needed to validate this method in pregnant women. There are also no specific data on the use of CRH or desmopressin in this population.

\section{Epillepsy}

In the subgroup of individuals with epilepsy, the best methods are late-night salivary/serum cortisol and 24-h UFC. Cortisol suppression tests with low-dose dexamethasone should be avoided due to an interference with dexamethasone metabolism by antiepileptic medications such as phenytoin, phenobarbital and carbamazepine, among others. In addition, carbamazepine metabolites can cause false positives results in 24-h UFC when analyzed by HPLC. One way to improve this accuracy is a concomitant dosage of serum dexamethasone, which should be higher than 140-220 ng/dL after $1 \mathrm{mg}$ overnight intake $(27,30)$, although its availability is limited.

\section{Renal insufficiency}

Traditionally, 24-h UFC should not be used for patients with renal insufficiency due to their decreased renal excretion with a reduced creatinine clearance of less than $60 \mathrm{ml} / \mathrm{min}$. In this subgroup of patients, late-night salivary cortisol or late-night serum cortisol should be used instead (100). A low-dose dexamethasone suppression test can be used with the same cutoff value of $1.8 \mu \mathrm{g} / \mathrm{dL}$.
However, with progressed reduction in creatinine clearance, there is a decreased excretion of dexamethasone, which may then lead to false negative results.

\section{Cyclical Cushing's syndrome}

The assessment of cyclical Cushing's syndrome is a major diagnostic and therapeutic challenge. This challenge is in part due to its low frequency, at approximately $15 \%$ of cases (101), but is also due to a great variability in the duration and interval between cycles, which can vary from days to years $(101,102)$. Importantly, diagnostic and etiological research should only be carried out in the presence of active hypercortisolism because tests are negative during the inactive phase of the disease. Because of this variability, several cortisol samples are usually necessary (24-h UFC or nocturnal salivary cortisol) to characterize the cycle, and late-night salivary cortisol is, therefore, the most practical (103).

The low-dose dexamethasone suppression test is not considered the best method, as it can have false negative results when performed in between cycles.

Recently, the utility of capillary (hair) cortisol has been evaluated with the goal of establishing a temporal characterization of the cortisol secretion in cyclic Cushing's syndrome (104).

\section{Adrenal incidentaloma}

The screening of Cushing's syndrome is formally indicated in the subgroup of patients with adrenal incidentaloma because $5.3-9.2 \%$ of the patients present subclinical Cushing's syndrome $(105,106)$. The recommended initial examination is a low-dose dexamethasone suppression test, using a cutoff of $1.8 \mu \mathrm{g} / \mathrm{dL}$ to optimize the sensitivity of the method (27). Other values, such as $5 \mu \mathrm{g} / \mathrm{dL}(107,108)$ or $3 \mu \mathrm{g} / \mathrm{dL}$ in an overnight $3 \mathrm{mg}$ test, increase the specificity of the method but reduce its sensitivity (109).

As an alternative, late-night salivary cortisol can be used, but it has shown less sensitivity when compared to the low-dose dexamethasone suppression test in this subgroup of patients $(57,110-113)$. Finally, with regard to first-line methods, 24-h UFC is the method with the highest number of false negative results, as it is diagnostic only when the disease is overt. Other test results may be useful, such as measurements of ACTH and DHEAS, which may be suppressed in these cases, as well as an attenuated response of ACTH and cortisol in the CRH test (27). 
Figure 1 shows a flowchart for the diagnosis of Cushing's syndrome.

\section{DIFFERENTIAL DIAGNOSIS OF ACTH-DEPENDENT CUSHING'S SYNDROME}

After a laboratorial confirmation of endogenous Cushing's syndrome, the subsequent diagnostic approach is to classify the syndrome according to the plasma ACTH levels: ACTH-dependent (ACTH higher than $20 \mathrm{pg} / \mathrm{mL}$ : CD vs. EAS) or ACTH-independent (ACTH less than $10 \mathrm{pg} / \mathrm{mL}$ : adenomas, carcinomas, or adrenal hyperplasia) Cushing's syndrome. Due to the non-regular secretion of ACTH, it is recommended to perform at least two measurements on different days to confirm the condition $(49,114)$. ACTH values in the range of $10-20 \mathrm{pg} / \mathrm{mL}$ are considered indeterminate, and new samples must be ordered.

Due to the scope of this recommendation manuscript, we will only address the differential diagnosis between CD and EAS.
CD represents $86-93 \%$ of the cases of ACTH-dependent Cushing's syndrome (115-117). Because of the high pretest probability of a CD diagnosis, $90 \%$ in women and $70 \%$ in men, diagnostic methods must ideally show an accuracy higher than $80-90 \%$.

Many methods are used for this purpose, although a triad is usually initially chosen: magnetic resonance imaging (MRI) of the pituitary, a CRH test, and a high-dose dexamethasone suppression test (HDDST). Whenever these three methods are not conclusive, bilateral and simultaneous inferior petrosal sinus sampling (BIPSS) remains the gold standard procedure for the differential diagnosis of CD and EAS (49,114,118-123).

\section{Pituitary MRI}

Pituitary MRI is usually the first exam to be ordered and remains the most important in defining the need for BIPSS. Due to the diagnostic difficulties and the necessity of sensitive methods, computerized tomography of the pituitary is not currently indicated, and

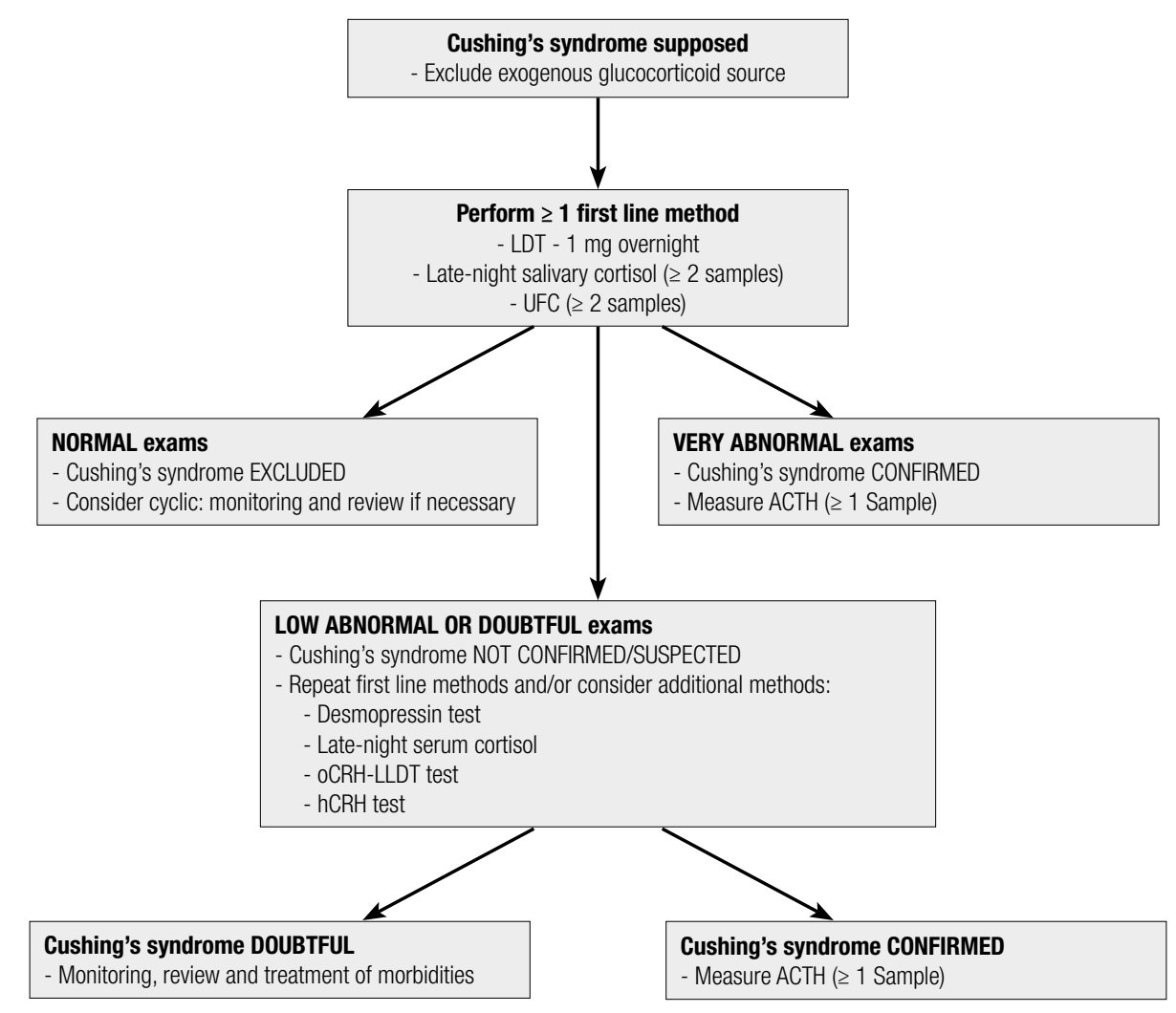

LDT: low-dose dexamethasone suppression test with 1 mg overnight; UFC: urinary free cortisol; oCRH: ovine; hCRH: human CRH; LLDT: Ionger low-dose dexamethasone suppression test (2 mg/day for $48 \mathrm{~h})$.

Figure 1. Flowchart of Cushing's syndrome diagnosis. 
a full cranium/brain MRI is considered not ideal for providing slices that are thin enough and focused to the sellar region.

$\mathrm{CD}$ is caused by pituitary microadenomas (less than $10 \mathrm{~mm}$ ) in $80-90 \%$ of such cases (5-7).

Conventional MRI spin echoes can present pitfalls such as artifacts (e.g., hyposignals of the pituitary parenchyma adjacent to the bony septum insertion of the sphenoid sinus in the sella floor) and the possibility of contrast uptake in the pituitary tumor. Therefore, the sensitivity of the conventional MRI spin echo is $50-60 \%$ (124), even for procedures using dynamic MRI.

In cases in which an expansive pituitary macroadenoma (greater than $10 \mathrm{~mm}$ ) is found, the diagnosis of $\mathrm{CD}$ is virtually confirmed. This presumed confirmation is important because this subset of patients may have a poorer response to a CRH test (125) and less suppression in the HDDST $(5,7,125,126)$.

Currently, a maximum diameter of more than $6 \mathrm{~mm}$ is suggestive of CD etiology $(22,49,118,121,123)$, especially for patients who respond to a CRH test and present cortisol suppression in the HDDST.

Other secondary findings from the MRI, although nonspecific, may also be helpful in diagnosing a microadenoma, such as deviations from the pituitary stalk, commonly to the opposite side of an expansive lesion, bulging of sella turcica or upper contours of the pituitary parenchyma, hyperintensity in the $\mathrm{T} 2$-weighted sequence by small intra-tumor cystic degeneration, and adjacent invasion of a cavernous sinus.

Thus, a patient with concordant tests suggestive of $\mathrm{CD}$, a pituitary image slightly smaller than $6 \mathrm{~mm}$ that is also coupled with the above-mentioned suggestive MRI findings, is usually sufficient to establish the diagnosis of a central source of ACTH. Finally, for those who have lesions smaller than $10 \mathrm{~mm}$ with or without secondary findings on the MRI but who show negative or inconclusive results on dynamic testing of ACTH and cortisol, BIPSS is recommended to establish or negate the diagnosis of CD.

To increase the pituitary MRI accuracy, other techniques have been sought for diagnostic improvement: spoiled gradient recalled acquisition (SPGR), which increases sensitivity through thinner slices $(1 \mathrm{~mm})$ and provides a more focused image resulting in a better soft tissue definition (124,127-129), has been tested, although it also increases the amount of artifacts and false positives. Additionally, 3-Tesla MRI (130-132) and other techniques have also been studied. More studies and a greater availability of these methods are needed to confirm their contribution to the diagnosis of CD.

\section{CRH test}

A CRH test is the best non-invasive dynamic test to differentiate CD from EAS. First identified in the 1980s (133), it has been extensively studied in this context. Most cases of CD respond significantly to CRH (8693\%) (1), whereas EAS patients respond in $5.5-8.2 \%$ of cases $(115,134)$. The enhanced responses to $\mathrm{CRH}$ in $\mathrm{CD}$ are as much due to deranged feedback as they are to an over-expression of $\mathrm{CRH}$ receptors.

The test is performed using ovine $\mathrm{CRH}$ (oCRH) or human CRH (hCRH). OCRH is the most studied peptide, as it has a more powerful and prolonged stimulus. Most commonly, a positive response is defined as an increase compared to baseline values (peak minus baseline) that is higher than $20 \%$ for cortisol and higher than $35 \%$ for ACTH with oCRH (135). For evaluations using hCRH, a positive response is considered for increases greater than $14 \%$ for cortisol and greater than $105 \%$ for ACTH $(85,86)$.

The study that defined the cutoff values for the hCRH test (higher than 14\% for cortisol and higher than $105 \%$ for ACTH) found a $70 \%$ and $85 \%$ sensitivity for ACTH and cortisol, respectively, and $100 \%$ specificity for each hormone (85).

The test is performed with an IV infusion of $1 \mu \mathrm{g} / \mathrm{kg}$ or $100 \mu \mathrm{g}$ of ovine or human CRH without prior dexamethasone suppression. The rationale for the test is based on the overexpression of the $\mathrm{CRH}$ receptor subtype 1 (CRHRl) in corticotropic tumors when compared to both normal pituitary tissue $(136,137)$ and tumors causing EAS (138). As mentioned previously, due to the high cost and unavailability of $\mathrm{CRH}$, the routine use of this method is limited.

\section{High-dose dexamethasone suppression test}

Of the initial triad, the HDDST is advantageous due to its availability and cost. However, it is the most questioned method in the literature due to its limited accuracy in differentiating between CD and EAS $(49,139)$.

The rationale behind this method is the preservation of negative feedback at higher doses of glucocorticosteroids in patients with corticotropic tumors. However, $25-30 \%$ of patients with EAS can also show the same pattern of cortisol suppression, leading to false positive results $(116,140)$. 
The HDDST is an old method ( $>50$ years) and was initially designed to measure cortisol metabolites in 24-h urine (17-OHCS) (141). Currently, it is performed through the measurement of serum cortisol between 8:00 am and 9:00 am before and after a highdose $(8 \mathrm{mg})$ oral night intake of dexamethasone and is considered suggestive of CD when a reduction of more than $50 \%$ is observed compared to the baseline value.

In brief, it can be performed with two protocols: $2 \mathrm{mg}$ of dexamethasone every 6 hours for two days ( 8 doses the classic method) or a simplified method with intake of a single $8 \mathrm{mg}$ overnight dose. The sensitivity and specificity of this method varies greatly due to the different protocols of dexamethasone administration used and to the different modes of cortisol analysis (urinary or serum).

To increase the specificity of the method, a more stringent criterion has been proposed for CD diagnosis, namely a greater than $80 \%$ cortisol suppression $(140,142)$. Using this criterion and the single intake of $8 \mathrm{mg}$ overnight, one study showed $100 \%$ specificity in a small group $(n=7)$ of patients with EAS, in which $28.6 \%$ of the patients suppressed cortisol at a level higher than $50 \%$. However, in this same study, only $56 \%$ of the 39 patients with CD showed greater than $80 \%$ suppression, for a total accuracy of only 63\% (140).

Finally, there has been an attempt to combine CRH response and the HDDST to increase the specificity of $\mathrm{CD}$ diagnoses. However, even the combination of the methods and the use of the most appropriate cutoff values has not provided enough accuracy to preclude the need for BIPSS in several cases.

\section{Bilateral and simultaneous inferior petrosal sinus sampling}

This method remains the gold standard for the differential diagnosis of ACTH-dependent Cushing's syndrome with an accuracy of approximately 90-98\% (143-145).

Bilateral and simultaneous inferior petrosal sinus sampling is indicated in cases where the triad of initial tests is inconclusive or discordant $(49,118-123)$ (Figure 2).

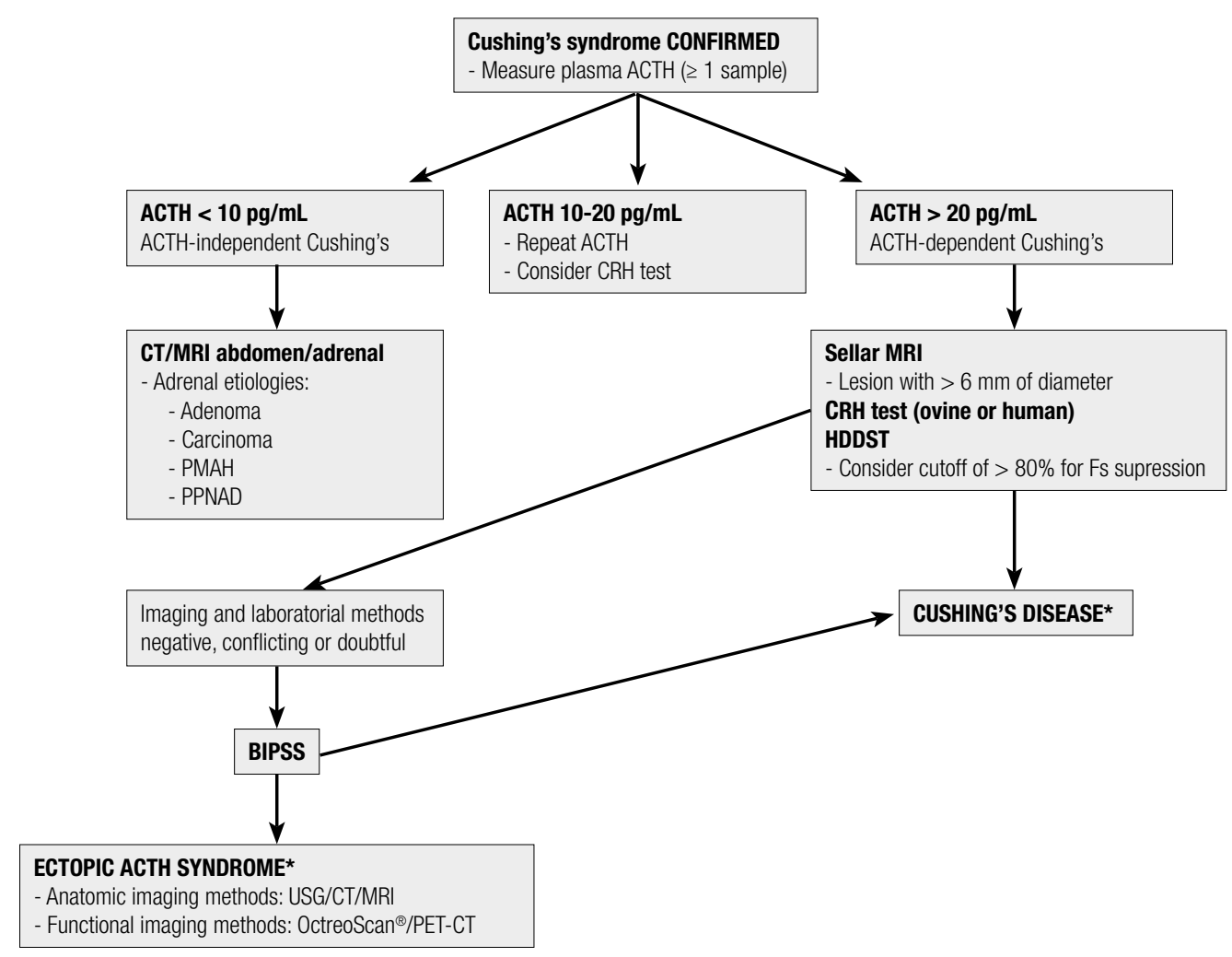

HDDST: high-dose dexamethasone suppression test (8 mg overnight); CT: computed tomography; MRI: magnetic resonance imaging; PMAH: primary macronodular adrenal hyperplasia; PPNAD: primary pigmented nodular adenocortical disease; BIPSS: bilateral and simultaneous petrosal sinus sampling; USG: ultrasound; PET-CT: positron emission tomography-computed tomography; * Even before the definition of Cushing's disease or EAS, anatomical images of the neck/chest/abdomen/pelvis are commonly obtained to contribute to the identification of the ACTH-producing source.

Figure 2. Flowchart for differential diagnosis of ACTH-dependent Cushing's syndrome 
False negatives can occur in approximately $5-10 \%$ of cases due to technical difficulties, anatomical variations such as plexiform presentation, unresponsiveness to secretagogues or use of drugs that modulate ACTH secretion. One study reported that false negatives only occurred in cases where the ACTH peak was lower than $400 \mathrm{pg} / \mathrm{mL}(145)$.

Fortunately, false positives are rare and can occur in cases of EAS during periods of normocortisolism (cyclical Cushing's syndrome or use of medical therapy for Cushing's) or in the rare case of ectopic CRH secretion (146).

This procedure should therefore be carried out in the presence of endogenous active hypercortisolism. Consequently, it is necessary to collect 24-h UFC and/ or nocturnal salivary cortisol in the evening of the test or in the preceding days to validate the procedure.

As it is an invasive procedure with potential side effects, the procedure should be performed in referral centers with highly skilled professionals.

Fortunately, the rate of serious complications such as cerebral vascular injury, deep venous thrombosis, pulmonary embolism, subarachnoid hemorrhage or cranial nerve paralysis has been very low or absent in many studies (147-150). The most common complications include bruising at the venipuncture site in $3-4 \%$ of the cases (147). Usually, a 5000 IU IV heparin infusion is recommended after the start of venous puncture (151).

The procedure is performed under stimulation of oCRH $(145,152)$, hCRH or desmopressin $(144,153,154)$ at the same doses as those used for dynamic secretion tests. Samples are taken at $0,3,5$ and 10 minutes after the stimulus, and the peak is usually 3 to $5 \mathrm{~min}$ after stimulus. The central to peripheral ACTH ratio, or the "central gradient", that is suggestive of CD etiology is defined as a ratio greater than 2 at baseline levels and/or higher than 3 at the peak.

Lateralization is defined as an interpetrosal gradient higher than 1.4 (152). However, lateralization is surgically confirmed in only approximately $60-80 \%$ of cases (1,155-157).

Furthermore, it is important to note that due to a high pretest probability of CD diagnosis, it is recommended to consider the possibility of a false negative result in cases without a central ACTH gradient.

Several aspects have to be observed during the procedure to ensure a reliable collection, including the following: successful catheterization, as confirmed by visualization of the intercavernous sinuses and contra- lateral petrosal sinus after contrast infusion; observation of anomalies or asymmetries in the petrosal sinus drainage $(123,146,158)$; and proper processing of the samples collected by storage in previously chilled plastic tubes with EDTA and immediate placement in an ice bath after collection.

Finally, recent studies have verified the prolactin values in BIPSS that can be used to correct for possible false negative gradients $(51,123,159,160)$. The values are initially obtained by calculating the central to peripheral prolactin gradient ipsilateral to the largest gradient of ACTH (baseline), which should be higher than 1.8. When the prolactin values are less than 1.8 , an unreliable collection of the inferior petrosal sinus should be considered. Subsequently, a ratio of the ACTH and ipsilateral prolactin gradients with cutoff values higher than 0.8 in one study (5l) and higher than 1.3 in another (123) have been suggested as indicative of a CD diagnosis.

Additionally, a recent study showed the utility of prolactin in improving tumor location by using the ratio of the interpetrosal gradient of ACTH and the interpetrosal gradient of prolactin (161). However, unlike the evaluation of prolactin in BIPSS, the role of prolactin evaluation in improving tumor location is still in its infancy, and further studies are thus needed to support its use.

\section{Desmopressin test}

The desmopressin test has been used for the differential diagnosis of ACTH-dependent Cushing's syndrome since 1993 (87). Subsequently, several studies have shown a response in the majority of patients with CD $(\sim 80 \%)(1)$. However, patients with EAS eventually also show a response, varying from $27-38 \%(1,116)$.

Desmopressin acts on both the AVPRIB (V3 or Vlb) $(137,162,163)$ and the AVPR2 (V2) $(162,164)$ vasopressin receptors, which have been documented to be overexpressed in corticotropic tumors when compared to both normal pituitary tissue and tumors causing EAS $(138,163,165,166)$.

The test is performed in the same way as that used to differentiate between Cushing's syndrome and pseudo-Cushing's (10 $\mu \mathrm{g}$ IV). An increase in cortisol higher than $20 \%$ and in ACTH higher than 35\% compared to baseline for both measures is considered predictive of $\mathrm{CD}$, similar to the oCRH test in the differential diagnosis between CD and EAS (135). 
However, due to the frequently observed response in patients with EAS, the desmopressin test should not be routinely performed to differentiate between the diagnoses of CD and EAS and should therefore be reserved to distinguish between Cushing's syndrome and pseudo-Cushing's or as a secretagogue in the BIPSS procedure.

\section{Other tests}

Other laboratory findings may be helpful in establishing a diagnosis of $\mathrm{CD}$ or EAS, although not conclusively: hypokalemia, present in $70 \%$ of EAS vs. $10 \%$ of CD patients due to cortisol mineralocorticoid activity in conditions of enzyme 11 $\beta$-HSD2 saturation; extremely high plasma ACTH concentrations ( $>400$ to 500 $\mathrm{pg} / \mathrm{mL}$; $>88$ to $110 \mathrm{pmol} / \mathrm{L}$ ) in EAS; positive tumor markers in EAS (examples: calcitonin, gastrin, chromogranin, $\beta$ hCG, alpha-fetoprotein, CEA, CA 19-9, CA 125) $(1,167)$; and measurement of pro-opiomelanocortin (POMC) and/or ACTH precursors $(168,169)$, which are commonly present in patients with EAS despite the poor availability of these measures.

\section{Diagnosis of EAS and search for ACTH-producing source}

The diagnosis of EAS can be made by identifying the ACTH-producing source through surgical documentation of the lesion with a positive immunohistochemistry for ACTH, clinical and laboratory remission of Cushing's syndrome after excision of the suspected lesion, or the absence of a center to peripheral ACTH gradient in a reliable BIPSS (not suggestive of a false negative result).

An ectopic source of ACTH can be first recognized by imaging studies ("overt") or recognized in follow-up with repeated imaging methods ("covert"), although it may also remain occult (8-27\%) $(115,116,134,170,171)$.

The most common causes of EAS are intrathoracic $(83 \%)(170)$, and bronchial/pulmonary carcinoid tumors are currently the most common etiologies $(115,116,134,171)$.

Thus, despite the stepwise diagnostic approach suggested in this manuscript, thoracic and abdominal imaging (CT or MRI) are commonly performed, as an evident suspicious lesion may prevent the need for a BIPSS procedure in a patient without visible pituitary imaging in MRI.

Finally, the search for a peripheral ACTH-producing source by imaging exams is indicated after a negative BIPSS for central gradient. The most common imaging methods are ultrasonography (USG), CT and MRI. These should be requested for the thoracic region (CT or MRI), abdomen/pelvis (CT or MRI), and cervical region (USG).

Somatostatin receptor scintigraphy with Indium $\left({ }^{111} \mathrm{In}\right.$-DTPA-octreotide, OctreoScan $\left.{ }^{\circledR}\right)$ is an important functional complementary method (172), although its sensitivity is not higher than that of plain images $(170,173,174)$, mainly due to the typically small size of bronchial carcinoid tumors (175).

PET-FDG ( ${ }^{18} \mathrm{~F}$ 2-deoxy-D-glucose), a test often used in oncology, may eventually be requested to localize ACTH-secreting tumors. Although some case reports have shown its usefulness $(176,177)$, larger detailed studies have shown that it has no advantage over anatomical tests $(170,178)$, probably due to the low metabolic activity of carcinoid tumors.

New forms of PET such as ${ }^{18} \mathrm{~F}$-DOPA-PET, scintigraphy with somatostatin analogues with new radionuclides such as Gallium $\left({ }^{68} \mathrm{Ga}\right)(179,180)$, and improvements in imaging techniques per se may increase the accuracy of functional imaging exams.

Regarding the follow-up of patients with occult EAS with tumors that have not been localized, after proper treatment for hypercortisolism, they should be submitted at least once a year to new anatomical imaging of the cervical and thoracic/abdominal/pelvic regions, with special consideration to the chest, as a ACTH-producing source may appear many years after the onset of symptoms, with bronchial carcinoid being the most common cause (181).

Table 6 summarizes the methods for establishing a differential diagnosis of ACTH-dependent Cushing's syndrome, and Figure 2 shows a flowchart of this differential diagnosis approach.

Disclosure: no potential conflict of interest relevant to this article was reported. 
Table 6. Methods for the differential diagnosis of ACTH-dependent Cushing's syndrome

\begin{tabular}{|c|c|c|c|c|}
\hline Method & Reference value & $\begin{array}{l}\text { Sensitivity } \\
\%\end{array}$ & $\begin{array}{l}\text { Specificity } \\
\%\end{array}$ & $\begin{array}{l}\text { Accuracy } \\
\%\end{array}$ \\
\hline Sellar MRI (spin echo) & - & $50-60$ & - & - \\
\hline Ovine $\mathrm{CRH}$ test (\% increase) $(1,115,134)$ & $\mathrm{ACTH}>35 \%$ and $\mathrm{Fs}>20 \%$ & $86-93$ & $92-94$ & - \\
\hline Human CRH test (\% increase) (85) & ACTH $>105 \%$ and $\mathrm{Fs}>14 \%$ & 70 and 85 & 100 & - \\
\hline High-dose dexamethasone suppression test (8 mg overnight) (1) & $>50 \%$ & $65-100$ & $65-100$ & - \\
\hline High-dose dexamethasone suppression test (8 mg overnight) (140) & $>80 \%$ & 56 & 100 & 63 \\
\hline $\begin{array}{l}\text { Bilateral and simultaneous petrosal sinus sampling (central to periphery ACTH gradient) } \\
(143,144)\end{array}$ & Baseline $\geq 2$ and/or peak $\geq 3$ & $90-95$ & $\sim 100$ & $90-94$ \\
\hline Other methods & \multicolumn{4}{|l|}{ Comments } \\
\hline Desmopressin test (increase of $\mathrm{ACTH}>35 \%$ and Fs $>20 \%$ ) & \multicolumn{4}{|c|}{ Low accuracy; should not be used routinely } \\
\hline K (hypokalemia) & \multicolumn{4}{|c|}{$70 \%$ EAS vs. $10 \%$ Cushing's disease } \\
\hline Plasma ACTH & \multicolumn{4}{|c|}{$\begin{array}{l}\text { Very high concentrations of ACTH (> 400-500 pg/mL) are suggestive of } \\
\text { EAS }\end{array}$} \\
\hline $\begin{array}{l}\text { Tumor markers (calcitonin, gastrin, chromogranin, } \beta \text { hCG, alfa-fetoprotein, CEA, CA 19-9, } \\
\text { CA125) }\end{array}$ & \multicolumn{4}{|c|}{$\begin{array}{l}\text { They can be measured (serum) or expressed (tissue) in up to } 70 \% \text { of EAS } \\
\text { cases }\end{array}$} \\
\hline POMC and/or ACTH precursors & \multicolumn{4}{|c|}{ Not available; does not guide the etiologic diagnosis of EAS } \\
\hline
\end{tabular}

Fs: serum cortisol; EAS: ectopic ACTH syndrome; POMC: pro-opiomelanocortin.

\section{REFERENCES}

1. Newell-Price J, Trainer P, Besser M, Grossman A. The diagnosis and differential diagnosis of Cushing's syndrome and pseudoCushing's states. Endocr Rev. 1998;19(5):647-72.

2. Stratakis CA. Cushing syndrome in pediatrics. Endocrinol Metab Clin North Am. 2012;41(4):793-803.

3. Steffensen C, Bak AM, Rubeck KZ, Jørgensen JO. Epidemiology of Cushing's syndrome. Neuroendocrinology. 2010;92 Suppl 1:1-5.

4. Beauregard C, Dickstein G, Lacroix A. Classic and recent etiologies of Cushing's syndrome: diagnosis and therapy. Treat Endocrinol. 2002;1(2):79-94.

5. Katznelson L, Bogan JS, Trob JR, Schoenfeld DA, Hedley-Whyte ET, Hsu DW, et al. Biochemical assessment of Cushing's disease in patients with corticotroph macroadenomas. J Clin Endocrinol Metab. 1998;83(5):1619-23.

6. Blevins LS Jr, Christy JH, Khajavi M, Tindall GT. Outcomes of therapy for Cushing's disease due to adrenocorticotropinsecreting pituitary macroadenomas. J Clin Endocrinol Metab. 1998;83(1):63-7.

7. Woo YS, Isidori AM, Wat WZ, Kaltsas GA, Afshar F, Sabin I, et al. Clinical and biochemical characteristics of adrenocorticotropinsecreting macroadenomas. J Clin Endocrinol Metab. 2005;90(8):4963-9.

8. Yaneva M, Vandeva S, Zacharieva S, Daly AF, Beckers A. Genetics of Cushing's syndrome. Neuroendocrinology. 2010;92 Suppl 1: 6-10.

9. Etxabe J, Vazquez JA. Morbidity and mortality in Cushing's disease: an epidemiological approach. Clin Endocrinol (Oxf). 1994;40(4):479-84.

10. Swearingen B, Biller BM, Barker FG 2nd, Katznelson L, Grinspoon $S$, Klibanski $A$, et al. Long-term mortality after transsphenoidal surgery for Cushing disease. Ann Intern Med. 1999;130(10):821-4.

11. Pikkarainen $L$, Sane $T$, Reunanen $A$. The survival and well-being of patients treated for Cushing's syndrome. J Intern Med. 1999;245(5):463-8.

12. Lindholm J, Juul S, Jørgensen JO, Astrup J, Bjerre P, FeldtRasmussen $U$, et al. Incidence and late prognosis of Cushing's syndrome: a population-based study. J Clin Endocrinol Metab. 2001;86(1):117-23.

13. Hammer GD, Tyrrell JB, Lamborn KR, Applebury CB, Hannegan ET, Bell $S$, et al. Transsphenoidal microsurgery for Cushing's disease: initial outcome and long-term results. J Clin Endocrinol Metab. 2004;89(12):6348-57.

14. Dekkers OM, Biermasz NR, Pereira AM, Roelfsema F, van Aken $\mathrm{MO}$, Voormolen $\mathrm{JH}$, et al. Mortality in patients treated for Cushing's disease is increased, compared with patients treated for nonfunctioning pituitary macroadenoma. J Clin Endocrinol Metab. 2007;92(3):976-81.

15. Clayton RN, Raskauskiene D, Reulen RC, Jones PW. Mortality and morbidity in Cushing's disease over 50 years in Stoke-onTrent, UK: audit and meta-analysis of literature. J Clin Endocrinol Metab. 2011;96(3):632-42.

16. Graversen D, Vestergaard P, Stochholm K, Gravholt CH, Jørgensen JO. Mortality in Cushing's syndrome: a systematic review and meta-analysis. Eur J Intern Med. 2012;23(3):278-82.

17. Lambert JK, Goldberg L, Fayngold S, Kostadinov J, Post KD, Geer EB. Predictors of mortality and long-term outcomes in treated Cushing's disease: a study of 346 patients. J Clin Endocrinol Metab. 2013;98(3):1022-30.

18. Dekkers OM, Horváth-Puhó E, Jørgensen JO, Cannegieter SC, Ehrenstein V, Vandenbroucke JP, et al. Multisystem morbidity and mortality in Cushing's syndrome: a cohort study. J Clin Endocrinol Metab. 2013;98(6):2277-84.

19. Yaneva M, Kalinov K, Zacharieva S. Mortality in Cushing's syndrome: data from 386 patients from a single tertiary referral center. Eur J Endocrinol. 2013;169(5):621-7.

20. Ntali G, Asimakopoulou A, Siamatras T, Komninos J, Vassiliadi $D$, Tzanela M, et al. Mortality in Cushing's syndrome: systematic analysis of a large series with prolonged follow-up. Eur J Endocrinol. 2013;169(5):715-23.

21. Flitsch J, Lüdecke DK, Knappe UJ, Grzyska U. Cavernous sinus sampling in selected cases of Cushing's disease. Exp Clin Endocrinol Diabetes. 2002;110(7):329-35.

22. Martínez Ruiz M, Gómez Bueno O, Molina Rodríguez MA, González Casado I, Gracia Bouthelier R. Diagnosis, treatment 
and long-term outcome in Cushing's disease. An Pediatr (Barc). 2003;59(2):183-6.

23. Bolland MJ, Holdaway IM, Berkeley JE, Lim S, Dransfield WJ, Conaglen JV, et al. Mortality and morbidity in Cushing's syndrome in New Zealand. Clin Endocrinol (Oxf). 2011;75(4):436-42.

24. Valassi E, Santos A, Yaneva M, Tóth M, Strasburger CJ, Chanson P, et al.; ERCUSYN Study Group. The European Registry on Cushing's syndrome: 2-year experience. Baseline demographic and clinical characteristics. Eur J Endocrinol. 2011;165(3):383-92.

25. Kreitschmann-Andermahr I, Psaras T, Tsiogka M, Starz D, Kleist B, Siegel S, et al. From first symptoms to final diagnosis of Cushing's disease: experiences of 176 patients. Eur J Endocrinol. 2015;172(3):285-9.

26. Costenaro F, Rodrigues TC, Rollin GA, Czepielewski MA. Assessment of the hypothalamic-pituitary-adrenal axis in Cushing's disease diagnosis and remission. Arq Bras Endocrinol Metabol. 2012;56(3):159-67.

27. Nieman LK, Biller BM, Findling JW, Newell-Price J, Savage MO, Stewart PM, et al. The diagnosis of Cushing's syndrome: an Endocrine Society Clinical Practice Guideline. J Clin Endocrinol Metab. 2008;93(5):1526-40.

28. Aron DC. Cushing's syndrome: why is diagnosis so difficult? Rev Endocr Metab Disord. 2010;11(2):105-16.

29. Beuschlein F, Hammer GD. Ectopic pro-opiomelanocortin syndrome. Endocrinol Metab Clin North Am. 2002;31(1):191-234.

30. Baid SK, Rubino D, Sinaii N, Ramsey S, Frank A, Nieman LK. Specificity of screening tests for Cushing's syndrome in an overweight and obese population. J Clin Endocrinol Metab. 2009;94(10):3857-64.

31. Karaca Z, Acmaz B, Acmaz G, Tanriverdi F, Unluhizarci K, Aribas $S$, et al. Routine screening for Cushing's syndrome is not required in patients presenting with hirsutism. Eur J Endocrinol. 2013;168(3):379-84.

32. Chiodini I, Mascia ML, Muscarella S, Battista C, Minisola S, Arosio $\mathrm{M}$, et al. Subclinical hypercortisolism among outpatients referred for osteoporosis. Ann Intern Med. 2007;147(8):541-8.

33. Carroll T, Raff H, Findling JW. Late-night salivary cortisol measurement in the diagnosis of Cushing's syndrome. Nat Clin Pract Endocrinol Metab. 2008;4(6):344-50.

34. Leibowitz G, Tsur A, Chayen SD, Salameh M, Raz I, Cerasi E, et al. Pre-clinical Cushing's syndrome: an unexpected frequent cause of poor glycaemic control in obese diabetic patients. Clin Endocrinol (Oxf). 1996;44(6):717-22.

35. Catargi B, Rigalleau V, Poussin A, Ronci-Chaix N, Bex V, Vergnot $\mathrm{V}$, et al. Occult Cushing's syndrome in type-2 diabetes. J Clin Endocrinol Metab. 2003;88(12):5808-13.

36. Chiodini I,Torlontano M, Scillitani A, Arosio M, Bacci S, Di Lembo $\mathrm{S}$, et al. Association of subclinical hypercortisolism with type 2 diabetes mellitus: a case-control study in hospitalized patients. Eur J Endocrinol. 2005;153(6):837-44.

37. Liu H, Bravata DM, Cabaccan J, Raff H, Ryzen E. Elevated latenight salivary cortisol levels in elderly male type 2 diabetic veterans. Clin Endocrinol (Oxf). 2005;63(6):642-9.

38. Caetano MS, Silva Rdo C, Kater CE. Increased diagnostic probability of subclinical Cushing's syndrome in a population sample of overweight adult patients with type 2 diabetes mellitus. Arq Bras Endocrinol Metabol. 2007;51(7):1118-27.

39. Reimondo G, Pia A, Allasino B, Tassone F, Bovio S, Borretta G, et al. Screening of Cushing's syndrome in adult patients with newly diagnosed diabetes mellitus. Clin Endocrinol (Oxf). 2007;67(2):225-9.

40. Newsome S, Chen K, Hoang J, Wilson JD, Potter JM, Hickman PE. Cushing's syndrome in a clinic population with diabetes. Intern Med J. 2008:38(3):178-82
41. TaniguchiT, Hamasaki A, Okamoto M. Subclinical hypercortisolism in hospitalized patients with type 2 diabetes mellitus. Endocr J. 2008;55(2):429-32.

42. Murakami H, Nigawara T, Sakihara S, Kageyama K, Yamashita M, Matsuki K, et al. The frequency of type 2 diabetic patients who meet the endocrinological screening criteria of subclinical Cushing's disease. Endocr J. 2010;57(3):267-72.

43. Mullan K, Black N, Thiraviaraj A, Bell PM, Burgess C, Hunter SJ, et al. Is there value in routine screening for Cushing's syndrome in patients with diabetes? J Clin Endocrinol Metab. 2010;95(5):2262-5.

44. Gagliardi L, Chapman IM, O'Loughlin P, Torpy DJ. Screening for subclinical Cushing's syndrome in type 2 diabetes mellitus: low false-positive rates with nocturnal salivary cortisol. Horm Metab Res. 2010;42(4):280-4.

45. Terzolo M, Reimondo G, Chiodini I, Castello R, Giordano R, Ciccarelli $E$, et al. Screening of Cushing's syndrome in outpatients with type 2 diabetes: results of a prospective multicentric study in Italy. J Clin Endocrinol Metab. 2012;97(10):3467-75.

46. Tabarin A, Perez P. Pros and cons of screening for occult Cushing syndrome. Nat Rev Endocrinol. 2011;7(8):445-55.

47. Fierabracci P, Pinchera A, Martinelli S, Scartabelli G, Salvetti G, Giannetti $M$, et al. Prevalence of endocrine diseases in morbidly obese patients scheduled for bariatric surgery: beyond diabetes. Obes Surg. 2011;21(1):54-60

48. Nonino-Borges CB, Martins Borges R, Bavaresco M, Suen VM, Moreira AC, Marchini JS. Influence of meal time on salivary circadian cortisol rhythms and weight loss in obese women. Nutrition. 2007;23(5):385-91.

49. Newell-Price J, Bertagna $X$, Grossman AB, Nieman LK. Cushing's syndrome. Lancet. 2006;367(9522):1605-17.

50. Pecori Giraldi F, Pivonello R, Ambrogio AG, De Martino MC, De Martin $M$, Scacchi $M$, et al. The dexamethasone-suppressed corticotropin-releasing hormone stimulation test and the desmopressin test to distinguish Cushing's syndrome from pseudo-Cushing's states. Clin Endocrinol (Oxf). 2007;66(2):251-7.

51. Findling JW, Raff H, Aron DC. The low-dose dexamethasone suppression test: a reevaluation in patients with Cushing's syndrome. J Clin Endocrinol Metab. 2004;89(3):1222-6.

52. Valassi $E$, Swearingen $B$, Lee $H$, Nachtigall LB, Donoho DA Klibanski $A$, et al. Concomitant medication use can confound interpretation of the combined dexamethasone-corticotropin releasing hormone test in Cushing's syndrome. J Clin Endocrinol Metab. 2009;94(12):4851-9.

53. Martinelli CE Jr, Sader SL, Oliveira EB, Daneluzzi JC, Moreira AC. Salivary cortisol for screening of Cushing's syndrome in children. Clin Endocrinol (Oxf). 1999;51(1):67-71.

54. Elamin MB, Murad MH, Mullan R, Erickson D, Harris K, Nadeem $S$, et al. Accuracy of diagnostic tests for Cushing's syndrome: a systematic review and metaanalyses. J Clin Endocrinol Metab. 2008;93(5):1553-62.

55. Castro M, Elias PC, Quidute AR, Halah FP, Moreira AC. Outpatient screening for Cushing's syndrome: the sensitivity of the combination of circadian rhythm and overnight dexamethasone suppression salivary cortisol tests. J Clin Endocrinol Metab. 1999;84(3):878-82.

56. Raff $\mathrm{H}$. Utility of salivary cortisol measurements in Cushing's syndrome and adrenal insufficiency. J Clin Endocrinol Metab. 2009;94(10):3647-55.

57. Raff $H$, Singh RJ. Measurement of late-night salivary cortisol and cortisone by LC-MS/MS to assess preanalytical sample contamination with topical hydrocortisone. Clin Chem. 2012;58(5):947-8.

58. Doi SA, Clark J, Russell AW. Concordance of the late night salivary cortisol in patients with Cushing's syndrome and elevated urinefree cortisol. Endocrine. 2013:43(2):327-33. 
59. Kidambi S, Raff H, Findling JW. Limitations of nocturnal salivary cortisol and urine free cortisol in the diagnosis of mild Cushing's syndrome. Eur J Endocrinol. 2007;157(6):725-31.

60. Elias PC, Martinez EZ, Barone BF, Mermejo LM, Castro M, Moreira AC. Late-night salivary cortisol has a better performance than urinary free cortisol in the diagnosis of Cushing's syndrome. $J$ Clin Endocrinol Metab. 2014;99(6):2045-51.

61. Barrou Z, Guiban D, Maroufi A, Fournier C, Dugué MA, Luton JP, et al. Overnight dexamethasone suppression test: comparison of plasma and salivary cortisol measurement for the screening of Cushing's syndrome. Eur J Endocrinol. 1996;134(1):93-6.

62. Carrasco CA, García M, Goycoolea M, Cerda J, Bertherat J, Padilla $\mathrm{O}$, et al. Reproducibility and performance of one or two samples of salivary cortisol in the diagnosis of Cushing's syndrome using an automated immunoassay system. Endocrine. 2012;41(3):487-93.

63. BelayaZE, IljinAV, Melnichenko GA, Rozhinskaya LY, Dragunova NV, Dzeranova LK, et al. Diagnostic performance of late-night salivary cortisol measured by automated electrochemiluminescence immunoassay in obese and overweight patients referred to exclude Cushing's syndrome. Endocrine. 2012;41(3):494-500.

64. Zerikly RK, Amiri L, Faiman C, Gupta M, Singh RJ, Nutter B, et al. Diagnostic characteristics of late-night salivary cortisol using liquid chromatography-tandem mass spectrometry. J Clin Endocrinol Metab. 2010;95(10):4555-9.

65. Erickson D, Singh RJ, Sathananthan A, Vella A, Bryant SC. Latenight salivary cortisol for diagnosis of Cushing's syndrome by liquid chromatography/tandem mass spectrometry assay. Clin Endocrinol (Oxf). 2012;76(4):467-72.

66. Inder WJ, Dimeski G, Russell A. Measurement of salivary cortisol in 2012 - laboratory techniques and clinical indications. Clin Endocrinol (Oxf). 2012;77(5):645-51.

67. Raff H. Update on late-night salivary cortisol for the diagnosis of Cushing's syndrome: methodological considerations. Endocrine. 2013;44(2):346-9.

68. Castro M, Moreira AC. Screening and diagnosis of Cushing's syndrome. Arq Bras Endocrinol Metabol. 2007;51(8):1191-8.

69. Castro M, Elias LL, Elias PC, Moreira AC. A dose-response study of salivary cortisol after dexamethasone suppression test in Cushing's disease and its potential use in the differential diagnosis of Cushing's syndrome. Clin Endocrinol (Oxf). 2003;59(6):800-5.

70. Deutschbein T, Unger N, Hinrichs J, Walz MK, Mann K, Petersenn S. Late-night and low-dose dexamethasone-suppressed cortisol in saliva and serum for the diagnosis of cortisol-secreting adrenal adenomas. Eur J Endocrinol. 2009;161(5):747-53.

71. Nieman LK, Cutler Jr GB. The sensitivity of the urine free cortisol measurement as a screening test for Cushing's syndrome. Presented at the 72th Annual Meeting of the Endocrine Society, 1990.

72. Petersenn S, Newell-Price J, Findling JW, Gu F, Maldonado M, Sen K, et al.; Pasireotide B2305 Study Group. High variability in baseline urinary free cortisol values in patients with Cushing's disease. Clin Endocrinol (Oxf). 2014;80(2):261-9.

73. Alexandraki $\mathrm{Kl}$, Grossman $\mathrm{AB}$. Is urinary free cortisol of value in the diagnosis of Cushing's syndrome? Curr Opin Endocrinol Diabetes Obes. 2011;18(4):259-63.

74. Batista DL, Riar J, Keil M, Stratakis CA. Diagnostic tests for children who are referred for the investigation of Cushing syndrome. Pediatrics. 2007;120(3):e575-86.

75. Chan LF, Storr HL, Grossman AB, Savage MO. Pediatric Cushing's syndrome: clinical features, diagnosis, and treatment. Arq Bras Endocrinol Metabol. 2007;51(8):1261-71.

76. Deutschbein T, Broecker-Preuss M, Hartmann MF, Althoff R, Wudy SA, Mann K, et al. Measurement of urinary free cortisol by current immunoassays: need for sex-dependent reference ranges to define hypercortisolism. Horm Metab Res. 2011;43(10):714-9.
77. Zilio M, Barbot M, Ceccato F, Camozzi V, Bilora F, Casonato A, et al. Diagnosis and complications of Cushing's disease: genderrelated differences. Clin Endocrinol (Oxf). 2014;80(3):403-10.

78. Papanicolaou DA, Yanovski JA, Cutler GB Jr, Chrousos GP, Nieman LK. A single midnight serum cortisol measurement distinguishes Cushing's syndrome from pseudo-Cushing states. J Clin Endocrinol Metab. 1998;83(4):1163-7.

79. Newell-Price J, Trainer P, Perry L, Wass J, Grossman A, Besser M. A single sleeping midnight cortisol has $100 \%$ sensitivity for the diagnosis of Cushing's syndrome. Clin Endocrinol (Oxf). 1995;43(5):545-50.

80. Pecori Giraldi F, Ambrogio AG, De Martin M, Fatti LM, Scacchi $M$, Cavagnini F. Specificity of first-line tests for the diagnosis of Cushing's syndrome: assessment in a large series. J Clin Endocrinol Metab. 2007;92(11):4123-9.

81. Yanovski JA, Cutler GB Jr, Chrousos GP, Nieman LK. Corticotropin-releasing hormone stimulation following lowdose dexamethasone administration. A new test to distinguish Cushing's syndrome from pseudo-Cushing's states. JAMA. 1993;269(17):2232-8.

82. Erickson D, Natt N, Nippoldt T, Young WF Jr, Carpenter PC, Petterson T, et al. Dexamethasone-suppressed corticotropinreleasing hormone stimulation test for diagnosis of mild hypercortisolism. J Clin Endocrinol Metab. 2007;92(8):2972-6.

83. Batista DL, Courcoutsakis N, Riar J, Keil MF, Stratakis CA. Severe obesity confounds the interpretation of low-dose dexamethasone test combined with the administration of ovine corticotrophinreleasing hormone in childhood Cushing syndrome. J Clin Endocrinol Metab. 2008;93(11):4323-30.

84. Reimondo G, Bovio S, Allasino B, De Francia S, Zaggia B, Micossi I, et al. The combined low-dose dexamethasone suppression corticotropin-releasing hormone test as a tool to rule out Cushing's syndrome. Eur J Endocrinol. 2008;159(5):569-76.

85. Newell-Price J, Morris DG, Drake WM, Korbonits M, Monson JP, Besser GM, et al. Optimal response criteria for the human $\mathrm{CRH}$ test in the differential diagnosis of ACTH-dependent Cushing's syndrome. J Clin Endocrinol Metab. 2002;87(4):1640-5.

86. Arnaldi G, Tirabassi G, Papa R, Furlani G, Trementino L, Cardinaletti $M$, et al. Human corticotropin releasing hormone test performance in the differential diagnosis between Cushing's disease and pseudo-Cushing state is enhanced by combined ACTH and cortisol analysis. Eur J Endocrinol. 2009;160(6):891-8.

87. Malerbi DA, Mendonça BB, Liberman B, Toledo SP, Corradini MC, Cunha-Neto MB, et al. The desmopressin stimulation test in the differential diagnosis of Cushing's syndrome. Clin Endocrinol (Oxf). 1993;38(5):463-72.

88. Malerbi DA, Fragoso MC, Vieira Filho AH, Brenlha EM, Mendonça BB. Cortisol and adrenocorticotropin response to desmopressin in women with Cushing's disease compared with depressive illness. J Clin Endocrinol Metab. 1996;81(6):2233-7.

89. Scott LV, Medbak S, Dinan TG. ACTH and cortisol release following intravenous desmopressin: a dose-response study. Clin Endocrinol (Oxf). 1999;51(5):653-8.

90. Tirabassi G, Faloia E, Papa R, Furlani G, Boscaro M, Arnaldi G. Use of the desmopressin test in the differential diagnosis of pseudo-Cushing state from Cushing's disease. J Clin Endocrinol Metab. 2010;95(3):1115-22.

91. Tirabassi G, Papa R, Faloia E, Boscaro M, Arnaldi G. Corticotrophinreleasing hormone and desmopressin tests in the differential diagnosis between Cushing's disease and pseudo-Cushing state: a comparative study. Clin Endocrinol (Oxf). 2011;75(5):666-72.

92. Rollin GA, Costenaro F, Gerchman F, Rodrigues TC, Czepielewski MA. Evaluation of the DDAVP test in the diagnosis of Cushing's disease. Clin Endocrinol (Oxf). 2015;82(6):793-800. 
93. Lindsay JR, Nieman LK. The hypothalamic-pituitary-adrenal axis in pregnancy: challenges in disease detection and treatment. Endocr Rev. 2005;26(6):775-99.

94. Lindsay JR, Jonklaas J, Oldfield EH, Nieman LK. Cushing's syndrome during pregnancy: personal experience and review of the literature. J Clin Endocrinol Metab. 2005;90(5):3077-83.

95. Bronstein MD, Paraiba DB, Jallad RS. Management of pituitary tumors in pregnancy. Nat Rev Endocrinol. 2011;7(5):301-10.

96. Pivonello R, De Martino MC, Auriemma RS, Alviggi C, Grasso LF, Cozzolino A, et al. Pituitary tumors and pregnancy: the interplay between a pathologic condition and a physiologic status. J Endocrinol Invest. 2014;37(2):99-112.

97. Jung C, Ho JT, Torpy DJ, Rogers A, Doogue M, Lewis JG, et al. A longitudinal study of plasma and urinary cortisol in pregnancy and postpartum. J Clin Endocrinol Metab. 2011;96(5):1533-40.

98. Viardot A, Huber P, Puder JJ, Zulewski H, Keller U, Müller B. Reproducibility of nighttime salivary cortisol and its use in the diagnosis of hypercortisolism compared with urinary free cortisol and overnight dexamethasone suppression test. J Clin Endocrinol Metab. 2005;90(10):5730-6.

99. Manetti L, Rossi G, Grasso L, Raffaelli V, Scattina I, Del Sarto $S$, et al. Usefulness of salivary cortisol in the diagnosis of hypercortisolism: comparison with serum and urinary cortisol. Eur J Endocrinol. 2013;168(3):315-21.

100. Wallace EZ, Rosman P, Toshav N, Sacerdote A, Balthazar A. Pituitary-adrenocortical function in chronic renal failure: studies of episodic secretion of cortisol and dexamethasone suppressibility. $\mathrm{J}$ Clin Endocrinol Metab. 1980;50(1):46-51.

101. Alexandraki KI, Kaltsas GA, Isidori AM, Akker SA, Drake WM, Chew SL, et al. The prevalence and characteristic features of cyclicity and variability in Cushing's disease. Eur $\mathrm{J}$ Endocrinol. 2009;160(6):1011-8.

102. Meinardi JR, Wolffenbuttel BH, Dullaart RP. Cyclic Cushing's syndrome: a clinical challenge. Eur J Endocrinol. 2007;157(3):245-54.

103. Graham UM, Hunter SJ, McDonnell M, Mullan KR, Atkinson AB. A comparison of the use of urinary cortisol to creatinine ratios and nocturnal salivary cortisol in the evaluation of cyclicity in patients with Cushing's syndrome. J Clin Endocrinol Metab. 2013;98(1):E72-6.

104. Manenschijn L, Koper JW, van den Akker EL, de Heide LJ, Geerdink $\mathrm{EA}$, de Jong $\mathrm{FH}$, et al. A novel tool in the diagnosis and follow-up of (cyclic) Cushing's syndrome: measurement of long-term cortisol in scalp hair. J Clin Endocrinol Metab. 2012;97(10):E1836-43.

105. Mantero F, Arnaldi G. Management approaches to adrenal incidentalomas. A view from Ancona, Italy. Endocrinol Metab Clin North Am. 2000;29(1):107-25.

106. Androulakis II, Kaltsas G, Piaditis G, Grossman AB. The clinical significance of adrenal incidentalomas. Eur $\mathrm{J}$ Clin Invest. 2011;41(5):552-60.

107. Terzolo M, Stigliano A, Chiodini I, Loli P, Furlani L, Arnaldi G, et al.; Italian Association of Clinical Endocrinologists. AME position statement on adrenal incidentaloma. Eur J Endocrinol. 2011;164(6):851-70.

108. Grumbach MM, Biller BM, Braunstein GD, Campbell KK, Carney JA, Godley PA, et al. Management of the clinically inapparent adrenal mass ("incidentaloma"). Ann Intern Med. 2003;138(5):424-9.

109. Reincke M. Subclinical Cushing's syndrome. Endocrinol Metab Clin North Am. 2000;29(1):43-56.

110. Nunes ML, Vattaut S, Corcuff JB, Rault A, Loiseau H, Gatta B, et al A. Late-night salivary cortisol for diagnosis of overt and subclinical Cushing's syndrome in hospitalized and ambulatory patients. J Clin Endocrinol Metab. 2009;94(2):456-62.
111. Masserini B, Morelli V, Bergamaschi S, Ermetici F, Eller-Vainicher C, Barbieri AM, et al. The limited role of midnight salivary cortisol levels in the diagnosis of subclinical hypercortisolism in patients with adrenal incidentaloma. Eur J Endocrinol. 2009;160(1):87-92.

112. Palmieri S, Morelli V, Polledri E, Fustinoni S, Mercadante R, Olgiati $L$, et al. The role of salivary cortisol measured by liquid chromatography-tandem mass spectrometry in the diagnosis of subclinical hypercortisolism. Eur J Endocrinol. 2013;168(3):28996.

113. Alencar GA, Lerario AM, Nishi MY, Mariani BM, Almeida MQ, Tremblay J, et al. ARMC5 mutations are a frequent cause of primary macronodular adrenal Hyperplasia. J Clin Endocrinol Metab. 2014;99(8):E1501-9.

114. Lacroix A, Feelders RA, Stratakis CA, Nieman LK. Cushing's syndrome. Lancet. 2015;386(9996):913-27.

115. Isidori AM, Kaltsas GA, Pozza C, Frajese V, Newell-Price J, Reznek $\mathrm{RH}$, et al. The ectopic adrenocorticotropin syndrome: clinical features, diagnosis, management, and long-term follow-up. J Clin Endocrinol Metab. 2006;91(2):371-7.

116. Salgado LR, Fragoso MC, Knoepfelmacher M, Machado MC, Domenice S, Pereira MA, et al. Ectopic ACTH syndrome: our experience with 25 cases. Eur J Endocrinol. 2006;155(5):725-33.

117. Tritos NA, Biller BM, Swearingen B. Management of Cushing disease. Nat Rev Endocrinol. 2011;7(5):279-89.

118. Newell-Price J. Diagnosis/differential diagnosis of Cushing's syndrome: a review of best practice. Best Pract Res Clin Endocrinol Metab. 2009;23 Suppl 1:S5-14.

119. Pivonello R, De Martino MC, De Leo M, Lombardi G, Colao A. Cushing's Syndrome. Endocrinol Metab Clin North Am. 2008;37(1):135-49.

120. Bertagna X, Guignat L, Groussin L, Bertherat J. Cushing's disease. Best Pract Res Clin Endocrinol Metab. 2009;23(5):607-23.

121. Munir A, Newell-Price J. Cushing's syndrome. Medicine. 2009;37(8):403-6.

122. Boscaro M, Arnaldi G. Approach to the patient with possible Cushing's syndrome. J Clin Endocrinol Metab. 2009;94(9):312131.

123. Sharma ST, Raff H, Nieman LK. Prolactin as a marker of successful catheterization during IPSS in patients with ACTH-dependent Cushing's syndrome. J Clin Endocrinol Metab. 2011;96(12):368794.

124. Patronas N, Bulakbasi N, Stratakis CA, Lafferty A, Oldfield EH, Doppman J, et al. Spoiled gradient recalled acquisition in the steady state technique is superior to conventional postcontrast spin echo technique for magnetic resonance imaging detection of adrenocorticotropin-secreting pituitary tumors. J Clin Endocrinol Metab. 2003;88(4):1565-9.

125. Ikeda H, Yoshimoto T, Ogawa Y, Mizoi K, Murakami O. Clinicopathological study of Cushing's disease with large pituitary adenoma. Clin Endocrinol (Oxf). 1997;46(6):669-79.

126. Selvais P, Donckier J, Buysschaert M, Maiter D. Cushing's disease: a comparison of pituitary corticotroph microadenomas and macroadenomas. Eur J Endocrinol. 1998;138(2):153-9.

127. Batista D, Courkoutsakis NA, Oldfield EH, Griffin KJ, Keil M, Patronas NJ, et al. Detection of adrenocorticotropin-secreting pituitary adenomas by magnetic resonance imaging in children and adolescents with cushing disease. J Clin Endocrinol Metab. 2005;90(9):5134-40.

128. Leães CG, Pereira-Lima JF, Lenhardt R, Silveira VM, Ferreira NP, Oliveira MC. Spoiled gradient recalled acquisition in the steady state for magnetic resonance imaging diagnosis of Cushing disease. Arq Neuropsiquiatr. 2009;67(1):127-9.

129. Kasaliwal R, Sankhe SS, Lila AR, Budyal SR, Jagtap VS, Sarathi $V$, et al. Volume interpolated 3D-spoiled gradient echo sequence 
is better than dynamic contrast spin echo sequence for MRI detection of corticotropin secreting pituitary microadenomas. Clin Endocrinol (Oxf). 2013;78(6):825-30.

130. Portocarrero-Ortiz L, Bonifacio-Delgadillo D, Sotomayor-González A, Garcia-Marquez A, Lopez-Serna R. A modified protocol using half-dose gadolinium in dynamic 3-Tesla magnetic resonance imaging for detection of ACTH-secreting pituitary tumors. Pituitary. 2010;13(3):230-5.

131. Ikeda $\mathrm{H}$, AbeT, Watanabe $\mathrm{K}$. Usefulness of composite methioninepositron emission tomography/3.0-tesla magnetic resonance imaging to detect the localization and extent of early-stage Cushing adenoma. J Neurosurg. 2010;112(4):750-5.

132. Erickson D, Erickson B, Watson R, Patton A, Atkinson J, Meyer $F$, et al. 3 Tesla magnetic resonance imaging with and without corticotropin releasing hormone stimulation for the detection of microadenomas in Cushing's syndrome. Clin Endocrinol (Oxf). 2010;72(6):793-9.

133. ValeW, Spiess J, Rivier C, Rivier J. Characterization of a 41-residue ovine hypothalamic peptide that stimulates secretion of corticotropin and beta-endorphin. Science. 1981;213(4514):13947.

134. Ilias I, Torpy DJ, Pacak K, Mullen N, Wesley RA, Nieman LK. Cushing's syndrome due to ectopic corticotropin secretion: twenty years' experience at the National Institutes of Health. J Clin Endocrinol Metab. 2005;90(8):4955-62.

135. Nieman LK, Oldfield EH, Wesley R, Chrousos GP, Loriaux DL, Cutler GB Jr. A simplified morning ovine corticotropin-releasing hormone stimulation test for the differential diagnosis of adrenocorticotropin-dependent Cushing's syndrome. J Clin Endocrinol Metab. 1993;77(5):1308-12.

136. Dieterich KD, Gundelfinger ED, Lüdecke DK, Lehnert H. Mutation and expression analysis of corticotropin-releasing factor 1 receptor in adrenocorticotropin-secreting pituitary adenomas. $\mathrm{J}$ Clin Endocrinol Metab. 1998;83(9):3327-31.

137. de Keyzer $Y$, René $P$, Beldjord $C$, Lenne $F$, Bertagna $X$. Overexpression of vasopressin (V3) and corticotrophin-releasing hormone receptor genes in corticotroph tumours. Clin Endocrinol (Oxf). 1998;49(4):475-82.

138. Tani $Y$, Sugiyama T, Izumiyama H, Yoshimoto T, Yamada S, Hirata Y. Differential gene expression profiles of POMC-related enzymes, transcription factors and receptors between non-pituitary and pituitary ACTH-secreting tumors. Endocr J. 2011;58(4):297-303.

139. Aron DC, Raff H, Findling JW. Effectiveness versus efficacy: the limited value in clinical practice of high dose dexamethasone suppression testing in the differential diagnosis of adrenocorticotropin-dependent Cushing's syndrome. J Clin Endocrinol Metab. 1997;82(6):1780-5.

140. Vilar L, Freitas MC, Naves LA, Canadas V, Albuquerque JL, Botelho $\mathrm{CA}$, et al. The role of non-invasive dynamic tests in the diagnosis of Cushing's syndrome. J Endocrinol Invest. 2008;31(11):1008-13.

141. Liddle GW. Tests of pituitary-adrenal suppressibility in the diagnosis of Cushing's syndrome. J Clin Endocrinol Metab. 1960;20:1539-60.

142. Aytug S, Laws ER Jr, Vance ML. Assessment of the utility of the high-dose dexamethasone suppression test in confirming the diagnosis of Cushing disease. Endocr Pract. 2012;18(2):152-7.

143. Linday JR, Nieman LK. Differential diagnosis and imaging in Cushing's syndrome. Endocrinol Metab Clin North Am. 2005;34(2):403-21.

144. Machado MC, de Sa SV, Domenice S, Fragoso MC, Puglia $P$ $\mathrm{Jr}$, Pereira MA, et al. The role of desmopressin in bilateral and simultaneous inferior petrosal sinus sampling for differential diagnosis of ACTH-dependent Cushing's syndrome. Clin Endocrinol (Oxf). 2007;66(1):136-42.
145. Wind JJ, Lonser RR, Nieman LK, DeVroom HL, Chang R, Oldfield $\mathrm{EH}$. The lateralization accuracy of inferior petrosal sinus sampling in 501 patients with Cushing's disease. J Clin Endocrinol Metab. 2013;98(6):2285-93.

146. Utz A, Biller BM. The role of bilateral inferior petrosal sinus sampling in the diagnosis of Cushing's syndrome. Arq Bras Endocrinol Metabol. 2007;51(8):1329-38.

147. Miller DL, Doppman JL, Peterman SB, Nieman LK, Oldfield EH, Chang R. Neurologic complications of petrosal sinus sampling. Radiology. 1992;185(1):143-7.

148. Lefournier V, Gatta B, Martinie M, Vasdev A, Tabarin A, Bessou $P$, et al O. One transient neurological complication (sixth nerve palsy) in 166 consecutive inferior petrosal sinus samplings for the etiological diagnosis of Cushing's syndrome. J Clin Endocrinol Metab. 1999;84(9):3401-2.

149. Bonelli FS, Huston J 3rd, Meyer FB, Carpenter PC. Venous subarachnoid hemorrhage after inferior petrosal sinus sampling for adrenocorticotropic hormone. AJNR Am J Neuroradiol. 1999;20(2):306-7.

150. Gandhi CD, Meyer SA, Patel AB, Johnson DM, Post KD. Neurologic complications of inferior petrosal sinus sampling. AJNR Am J Neuroradiol. 2008;29(4):760-5.

151. Puglia Jr P, Caldas JG, Barbosa LA, Sá Jr AT, Machado MC, Salgado LR. Inferior petrosal sinus catheterization: technical aspects. Arq Bras Endocrinol Metabol. 2008;52(4):692-6.

152. Oldfield EH, Doppman JL, Nieman LK, Chrousos GP, Miller DL, Katz DA, et al. Petrosal sinus sampling with and without corticotropin-releasing hormone for the differential diagnosis of Cushing's syndrome. N Engl J Med. 1991;325(13):897-905.

153. Castinetti F, Morange I, Dufour H, Jaquet P, Conte-Devolx B, Girard $\mathrm{N}$, et al. Desmopressin test during petrosal sinus sampling: a valuable tool to discriminate pituitary or ectopic $\mathrm{ACTH}$-dependent Cushing's syndrome. Eur J Endocrinol. 2007;157(3):271-7.

154. Deipolyi AR, Hirsch JA, Oklu R. Bilateral inferior petrosal sinus sampling. J Neurointerv Surg. 2012;4(3):215-8.

155. Invitti C, Pecori Giraldi F, de Martin M, Cavagnini F. Diagnosis and management of Cushing's syndrome: results of an Italian multicentre study. Study Group of the Italian Society of Endocrinology on the Pathophysiology of the HypothalamicPituitary-Adrenal Axis. J Clin Endocrinol Metab. 1999;84(2):440-8.

156. Colao A, Faggiano A, Pivonello R, Pecori Giraldi F, Cavagnini F, Lombardi G; Study Group of the Italian Endocrinology Society on the Pathophsiology of the Hypothalamic-Pituitary-Adrenal Axis. Inferior petrosal sinus sampling in the differential diagnosis of Cushing's syndrome: results of an Italian multicenter study. Eur J Endocrinol. 2001;144(5):499-507.

157. Lefournier V, Martinie M, Vasdev A, Bessou P, Passagia JG, LabatMoleur $F$, et al. Accuracy of bilateral inferior petrosal or cavernous sinuses sampling in predicting the lateralization of Cushing's disease pituitary microadenoma: influence of catheter position and anatomy of venous drainage. J Clin Endocrinol Metab. 2003;88(1):196-203.

158. Mamelak AN, Dowd CF, Tyrrell JB, McDonald JF, Wilson CB. Venous angiography is needed to interpret inferior petrosal sinus and cavernous sinus sampling data for lateralizing adrenocorticotropin-secreting adenomas. J Clin Endocrinol Metab. 1996;81(2):475-81.

159. Daousi C, Nixon T, Javadpour M, Hayden K, MacFarlane IA. Inferior petrosal sinus ACTH and prolactin responses to $\mathrm{CRH}$ in ACTH-dependent Cushing's syndrome: a single centre experience from the United Kingdom. Pituitary. 2010;13(2):95-104.

160. Grant P, Dworakowska D, Carroll P. Maximizing the accuracy of inferior petrosal sinus sampling: validation of the use of prolactin 
as a marker of pituitary venous effluent in the diagnosis of Cushing's disease. Clin Endocrinol (Oxf). 2012;76(4):555-9.

161. Mulligan GB, Faiman C, Gupta M, Kennedy L, Hatipoglu B, Hui $F$, et al. Prolactin measurement during inferior petrosal sinus sampling improves the localization of pituitary adenomas in Cushing's disease. Clin Endocrinol (Oxf). 2012;77(2):268-74.

162. Dahia PL, Ahmed-Shuaib A, Jacobs RA, Chew SL, Honegger J, Fahlbusch $\mathrm{R}$, et al. Vasopressin receptor expression and mutation analysis in corticotropin-secreting tumors. J Clin Endocrinol Metab. 1996;81(5):1768-71.

163. Machado MC, Valeria de Sa S, Correa-Giannella ML, Giorgi RR, Pereira MA, Cescato VA, et al. Association between tumoral GHreleasing peptide receptor type 1a mRNA expression and in vivo response to $\mathrm{GH}$-releasing peptide- 6 in ACTH-dependent Cushing's syndrome patients. Eur J Endocrinol. 2008;158(5):605-13.

164. Wang FF, Tang KT, Yen YS, Ho DM, Yang $\mathrm{AH}$, Huang $\mathrm{Cl}$, et al. Plasma corticotrophin response to desmopressin in patients with Cushing's disease correlates with the expression of vasopressin receptor 2, but not with that of vasopressin receptor 1 or 3 , in their pituitary tumours. Clin Endocrinol (Oxf). 2012;76(2):253-63.

165. Tsagarakis S, Tsigos C, Vasiliou V, Tsiotra P, Kaskarelis J, Sotiropoulou $\mathrm{C}$, et al. The desmopressin and combined $\mathrm{CRH}$ desmopressin tests in the differential diagnosis of ACTHdependent Cushing's syndrome: constraints imposed by the expression of V2 vasopressin receptors in tumors with ectopic ACTH secretion. J Clin Endocrinol Metab. 2002;87(4):1646-53.

166. Messager M, Carrière $C$, Bertagna $X$, de KeyzerY. RT-PCR analysis of corticotroph-associated genes expression in carcinoid tumours in the ectopic-ACTH syndrome. Eur $\mathrm{J}$ Endocrinol. 2006;154(1):159-66.

167. Zemskova MS, Nylen ES, Patronas NJ, Oldfield EH, Becker $\mathrm{KL}$, Nieman LK. Diagnostic accuracy of chromogranin $\mathrm{A}$ and calcitonin precursors measurements for the discrimination of ectopic ACTH secretion from Cushing's disease. J Clin Endocrinol Metab. 2009;94(8):2962-5.

168. Raffin-Sanson ML, Massias JF, Dumont C, Raux-Demay MC, Proeschel MF, Luton JP, et al. High plasma proopiomelanocortin in aggressive adrenocorticotropin-secreting tumors. J Clin Endocrinol Metab. 1996;81(12):4272-7.

169. Oliver RL, Davis JR, White A. Characterisation of ACTH related peptides in ectopic Cushing's syndrome. Pituitary. 2003;6(3):11926.

170. Zemskova MS, Gundabolu B, Sinaii N, Chen CC, Carrasquillo JA, Whatley $M$, et al. Utility of various functional and anatomic imaging modalities for detection of ectopic adrenocorticotropinsecreting tumors. J Clin Endocrinol Metab. 2010;95(3):1207-19.

171. Ejaz S, Vassilopoulou-Sellin R, Busaidy NL, Hu MI, Waguespack SG, Jimenez $C$, et al. Cushing syndrome secondary to ectopic adrenocorticotropic hormone secretion: the University of Texas MD Anderson Cancer Center Experience. Cancer. $2011 ; 117(19): 4381-9$.
172. Tsagarakis S, Christoforaki M, Giannopoulou H, Rondogianni F, Housianakou I, Malagari $C$, et al. A reappraisal of the utility of somatostatin receptor scintigraphy in patients with ectopic adrenocorticotropin Cushing's syndrome. J Clin Endocrinol Metab. 2003;88(10):4754-8.

173. Tabarin A, Valli N, Chanson P, BachelotY, RohmerV, Bex-Bachellerie $\mathrm{V}$, et al. Usefulness of somatostatin receptor scintigraphy in patients with occult ectopic adrenocorticotropin syndrome. J Clin Endocrinol Metab. 1999;84(4):1193-202.

174. Torpy DJ, Chen CC, Mullen N, Doppman JL, Carrasquillo JA, Chrousos GP, et al. Lack of utility of (111)/n-pentetreotide scintigraphy in localizing ectopic ACTH producing tumors: followup of 18 patients. J Clin Endocrinol Metab. 1999;84(4):1186-92.

175. Alexandraki KI, Grossman AB. The ectopic ACTH syndrome. Rev Endocr Metab Disord. 2010;11(2):117-26.

176. Moraes AB, Taboada GF, Carneiro MP, Neto LV, Wildemberg LE, Madi K, et al. Utility of [(18)F] fluoro-2-deoxy-D: -glucose positron emission tomography in the localization of ectopic ACTHsecreting tumors. Pituitary. 2009;12(4):380-3.

177. Moreno-Fernández J, Gutiérrez-Alcántara C, Gálvez Moreno MA, Jiménez-Reina L, Castaño JP, Benito-López P. Corticotrophindependent Cushing syndrome due to Sacrococcygeal Teratoma detected by [18F]fluorodeoxyglucose positron emission tomography. J Clin Endocrinol Metab. 2008;93(9):3282-3.

178. Pacak K, Ilias I, Chen CC, Carrasquillo JA, Whatley M, Nieman LK. The role of [(18)F]fluorodeoxyglucose positron emission tomography and $[(111) \mid n]$-diethylenetriaminepentaacetate-DPhe-pentetreotide scintigraphy in the localization of ectopic adrenocorticotropin-secreting tumors causing Cushing's syndrome. J Clin Endocrinol Metab. 2004;89(5):2214-21.

179. Därr R, Zöphel K, Eisenhofer G, Abolmaali N, Gastmeier J, Wieczorek K, et al. Combined use of 68Ga-DOTATATE and 18F-FDG $\mathrm{PET} / \mathrm{CT}$ to localize a bronchial carcinoid associated with ectopic ACTH syndrome. J Clin Endocrinol Metab. 2012;97(7):2207-8.

180. Veit JA, Boehm B, Luster M, Scheuerle A, Rotter N, Rettinger G, et al. Detection of paranasal ectopic adrenocorticotropic hormonesecreting pituitary adenoma by Ga-68-DOTANOC positronemission tomography-computed tomography. Laryngoscope. 2013;123(5):1132-5.

181. Sookur PA, Sahdev A, Rockall AG, Isidori AM, Monson JP, Grossman $A B$, et al. Imaging in covert ectopic ACTH secretion: a CT pictorial review. Eur Radiol. 2009;19(5):1069-78.

182. Vassiliadi D,Tsagarakis S. Unusual causes of Cushing's syndrome. Arq Bras Endocrinol Metabol. 2007;51(8):1245-52.

183. Kelly W. Exophthalmos in Cushing's syndrome. Clin Endocrinol (Oxf). 1996;45(2):167-70.

184. Magiakou MA, Mastorakos G, Oldfield EH, Gomez MT, Doppman $\mathrm{JL}$, Cutler GB Jr, et al. Cushing's syndrome in children and adolescents. Presentation, diagnosis, and therapy. N Engl J Med. 1994;331(10):629-36. 